SPECIAL EDUCATION TRANSITION: PREPARING STUDENTS WITH LEARNING DISABILITIES FOR POST-SECONDARY EDUCATION

\author{
A Dissertation submitted to the faculty of \\ San Francisco State University \\ In partial fulfillment of \\ the requirements for \\ the Degree \\ Doctor of Education
}

AS

35

2016

EDD

- J36
In

Educational Leadership

by

Julie L. Jang

San Francisco, California

Fall 2016 
Copyright by Julie L. Jang 2016 


\section{CERTIFICATION OF APPROVAL}

I certify that I have read Special Education Transition: Preparing Students with Learning Disabilities for Post-Secondary Education by Julie L. Jang and that in my opinion this work meets the criteria for approving a dissertation submitted in partial fulfillment of the requirement for the degree Doctorate of Education in Educational Leadership at San Francisco State University.

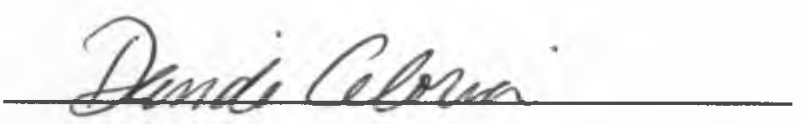

Davide Celoria, Ed.D.

Assistant Professor, Equity, Leadership

Studies, and Instructional Technologies

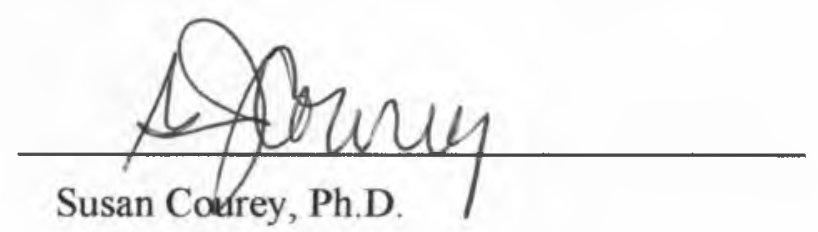

Touro University

Associate Professor, Special Education

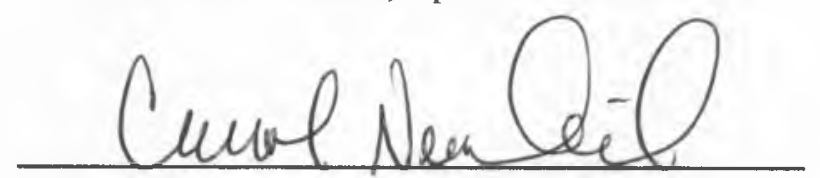

Carol Newkirk-Sakaguchi, M.S.

Learning Disabilities Specialist

Skyline College 


\title{
SPECIAL EDUCATION TRANSITION: PREPARING STUDENTS WITH LEARNING DISABILITIES FOR POST-SECONDARY EDUCATION
}

\author{
Julie L. Jang \\ San Francisco, California \\ 2016
}

The central focus of this study explores the transition of students with learning disabilities from high school to community college. Although students with learning disabilities are entitled to transition services as highlighted in ADA, OCR, and IDEA, there are limited programs available in California to support students with learning disabilities transitioning from high school to community college. Using SelfDetermination Theory (SDT) as a framework, this mixed methods study employs the use of the ARC Self-Determination Scale and semi-structured interviews to identify and explore the essential characteristics needed for students with learning disabilities to successfully transition from high school to college. Recommendations for the preparation of students with learning disabilities to successfully transition from high school to college are also explored.

I certify that the Abstract is a correct representation of the content of this dissertation.

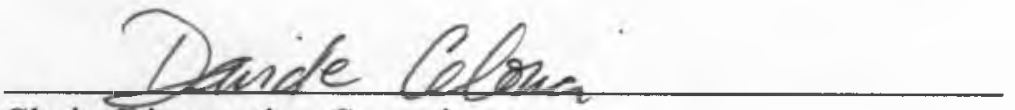

Chair, Dissertation Committee

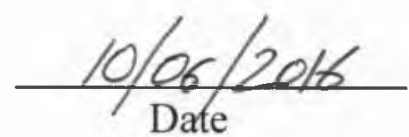




\section{ACKNOWLEDGEMENTS}

I would like to first acknowledge and thank the members of my committee: Dr. Davide Celoria, Dr. Susan Courey, and Carol Newkirk-Sakaguchi for your guidance. I especially want to thank Dr. Celoria who supported me, pushed me, and never gave up on me.

I would like to give a big acknowledgement of gratitude to my beloved cohort who made the past three years fly by so quickly. I will miss our meetings and our time in and out of class. Thank you so much for everything.

I would also like to acknowledge my mother who supported me by making sure that I had everything I needed to get through work and school. She may not have understood this program but she understood that it was important to me. I love you Mom.

Finally, I dedicate this to all of my students with learning disabilities who inspired me and gave me my purpose, focus, and passion to pursue this project. 


\section{TABLE OF CONTENTS}

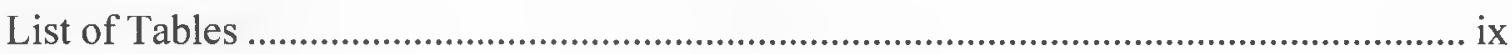

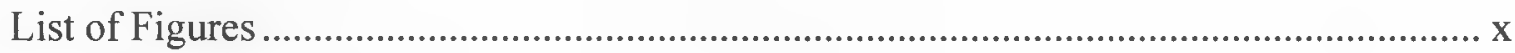

List of Appendices ......................................................................................................... xi

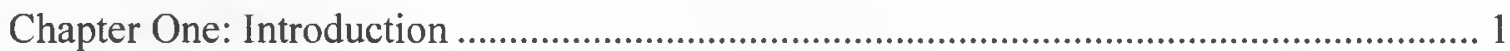

Statement of Educational Problem.................................................................... 2

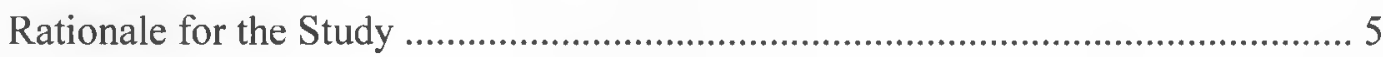

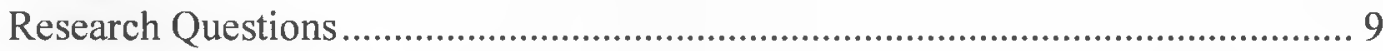

Conceptual Framework …................................................................................. 9

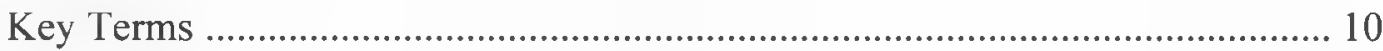

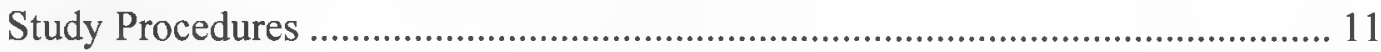

Chapter Two: Literature Review ...................................................................................... 13

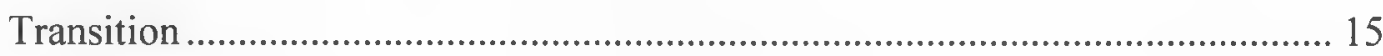

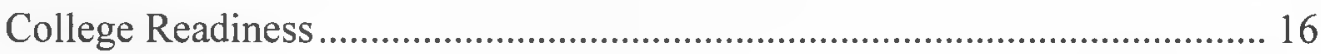

Disability Awareness .............................................................................. 18

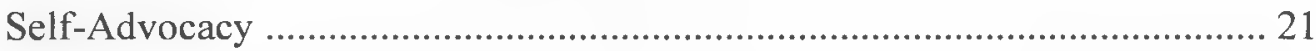

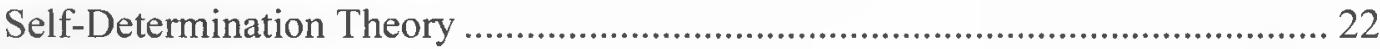

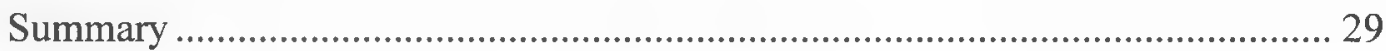

Chapter Three: Methodology …………......................................................................... 31

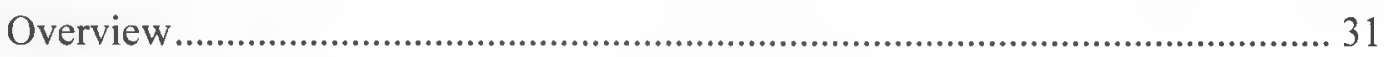

Rationale for a Mixed Methods Design ................................................................... 32

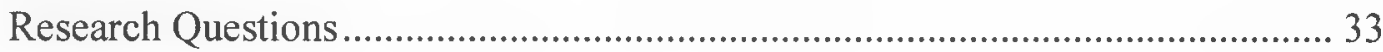


Target Population and Participants 34

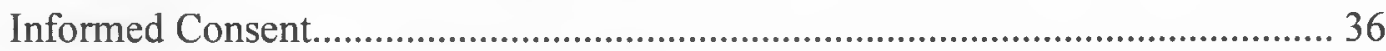

Instrumentation (Survey and Interview Protocol)................................................. 36

The ARC Scale Surveys (Quantitative Instrumentation) ........................................ 38

Qualitative Instrumentation (Interview Protocol) ................................................... 40

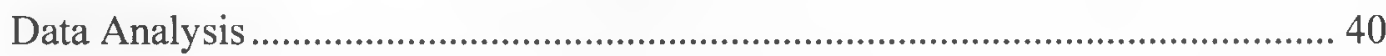

Chapter Four: Report of Findings ................................................................................ 43

Southeast High School ........................................................................................... 45

Pacific Community College................................................................................... 49

High School Preparation .................................................................................... 52

College Readiness Skills.................................................................................. 54

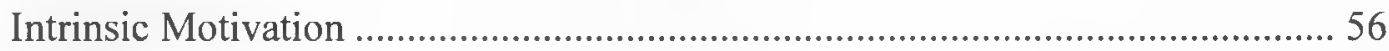

Disability Awareness ........................................................................................... 59

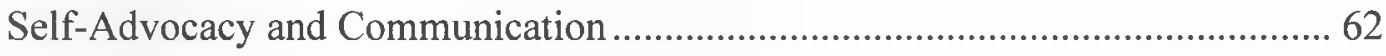

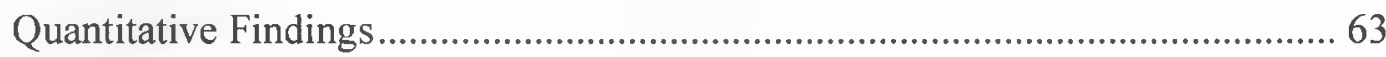

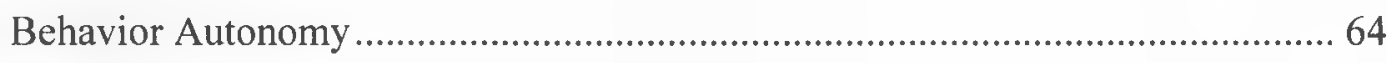

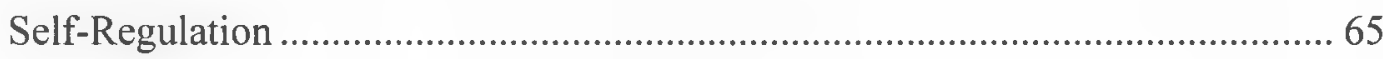

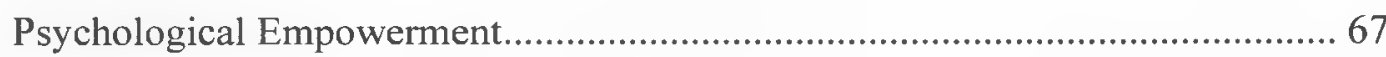

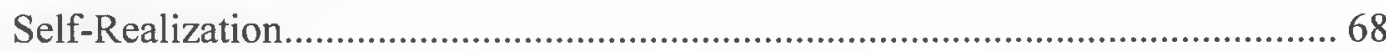

Self-Determination, A Predictor of Academic Success .......................................... 69

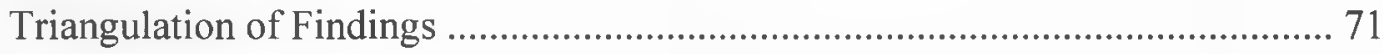

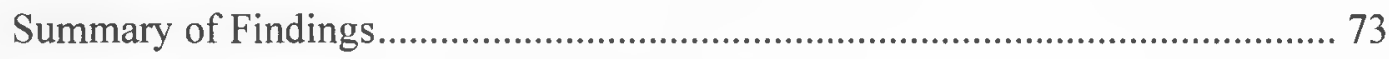

Chapter Five: Discussion and Recommendations........................................................... 76

High School Preparation................................................................................. 76 
College Readiness Skills

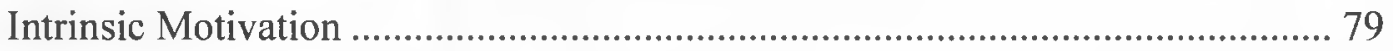

Relationships, Relatedness, and Awareness ....................................................... 81

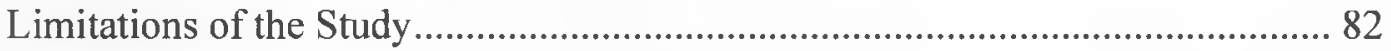

Implications for Further Research and Practice............................................... 85

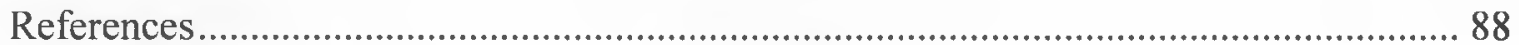

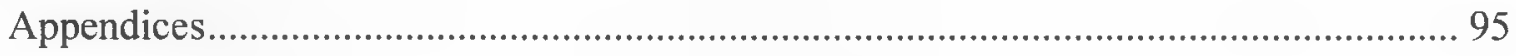




\section{LIST OF TABLES}

Table

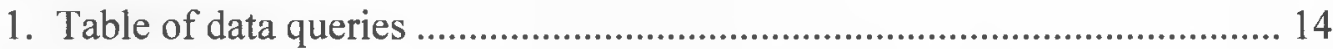

2. Spreadsheet of ARC Scales and subscales ................................................... 39

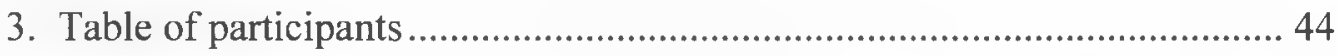

4. Graph of characteristics of self-determination .............................................. 59

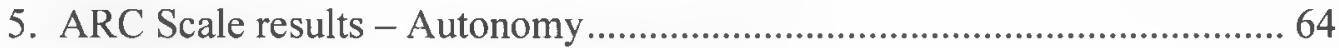

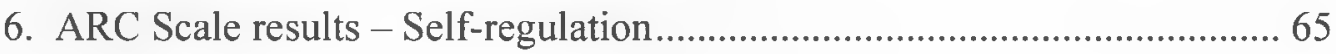

7. ARC Scale results - Psychological empowerment ………………................67 67

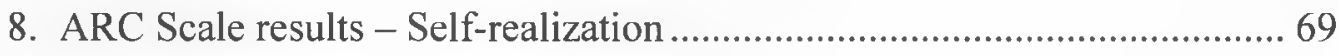

9. Comparison of ARC Self-Determination and GPA ……………………..... 70 


\section{LIST OF FIGURES}

\section{Figures}

1. Goal setting and task performance on ARC Scale 


\section{LIST OF APPENDICES}

Appendix

Page

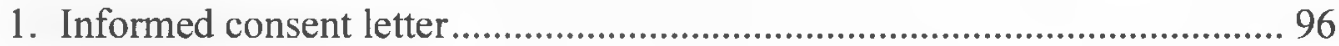

2. The ARC Self-Determination Scale ..................................................... 99

3. Semi-structured interview protocol ................................................ 104 


\section{Chapter 1: Introduction}

The purpose of the study was to identify and better understand the characteristics important for the successful transition of students with learning disabilities from high school to community college. The study was driven by the awareness that the transition from high school to postsecondary education can be a challenging time for all students, and even more challenging for students with learning disabilities. According to Gregg (2007) "...students with learning disabilities (LD) continue to be underserved and underprepared to meet the demands of postsecondary education. Evidence pertaining to postsecondary education outcomes for the population with LD is extremely bleak" (p. 219). A recent study on first-generation college students with disabilities found students with disabilities had lower GPAs, less family and peer support, and experienced greater financial stress than students without disabilities (Lombardi, Murray, \& Gerdes, 2012). In addition, high school graduates with learning disabilities are less likely to attend postsecondary institutions, and those who do attend have comparatively low success rates (Abreu-Ellis, Ellis, \& Hayes, 2009).

Students with learning disabilities tend to arrive on college and university campuses with varying levels of skill and preparation, particularly in the areas of academics and social skills (Abreu-Ellis, Ellis, \& Hayes, 2009). They tend to be more vulnerable during the transition from high school to college than students without disabilities, and they must be able to navigate their disability challenges with the 
academic demands of college, social expectations such as peer and faculty relationships, and their own personal growth (Connor, 2012). According to Patrick and Wessel (2013), the successful transition to postsecondary education is directly related to the students' ability to transition from their former communities (high school, family, and the like) into the college community setting. This involves accommodating both academically and socially in a new environment as they take on a new identity: a college student.

\section{Statement of Educational Problem}

Despite a recent rise in enrollment, students with disabilities are underrepresented in community colleges (Abreu-Ellis et al., 2009; Cortiella and Howowitz, 2014). Researchers attribute this to low expectations placed on students with learning disabilities, poor high school preparation and transition planning, lack of communication and support services, and ineffective support from school faculty (Garrison-Wade \& Lehmann, 2009). About $31 \%$ of students with disabilities enroll in postsecondary coursework; however, their persistence rates are low. Only about 19\% of students with disabilities continue to persist in postsecondary settings compared to $40 \%$ of students without disabilities (Morningstar et al., 2010).

The success rates for students with disabilities are also comparatively low, even as the number of students with learning disabilities attending postsecondary institutions is on the rise (Abreu-Ellis et al., 2009). Moreover, the dropout rate of students with learning disabilities also remains extremely high compared to students without 
disabilities (Denhart, 2008). As a result, students with disabilities do not earn degrees at the same rate as students without disabilities (Finn, Getzel, \& McManus 2008) however rates are starting to rise. According to Anctil, Ishikawa, and Scott (2008), only 16\% of college students with disabilities earned a bachelor's degree, compared to $27 \%$ of those without a disability in 2008. Whereas Cortiella and Horowitz (2014) reported that the college completion rate for students with learning disabilities is about 41 percent whereas 52 percent of students without a disability completed college.

Non-DS faculty at the college level are also less prepared to teach students with learning disabilities than high school teachers. College professors tend to be content experts and not always prepared to teach students with disabilities. According to Garrison-Wade and Lehmann (2009), faculty and staff at community colleges, with exception of disability resource service providers, have little experience or training about disabilities. Building the capacity for community college and university faculty should include understanding the general criteria for all disabilities, especially those that are not physically evident. This includes professional development on universal design and to address services and accommodations available to enhance student learning, particularly students with specific learning disabilities. Because learning disabilities are hidden, the needs of students with learning disabilities are not as readily understood as the needs of students with more evident disabilities, such as deafness or blindness, orthopedic impairments, autism, or intellectual disabilities. Learning-disabled students also often 
deny their learning challenges and may not seek the accommodations they need to succeed in college (Janiga \& Costenbader, 2002). According to Cortiella and Howowitz (2014):

The vast majority of young adults who received special education services for LD in high school did not consider themselves to have a disability within eight years of leaving high school... Within two years of leaving high school, half ( 52 percent) did not consider themselves to have a disability. [Only] a small percentage of young adults with LD who considered themselves to have a disability, disclosed their disability to the school and received accommodations and supports. The lack of disclosure by a majority of students likely has a negative impact on college completion. In sharp contrast, 94 percent of students with $L D$ received some type of accommodation or support during high school (p. 20).

Additionally, there are a limited number of programs available in California to support students with learning disabilities transitioning from high school to community college. Although high school transition specialists are available within high school districts, many of these specialists focus on a variety of transitions including employment, independent living, vocational schooling, and career planning. College planning is only a small element of the range of options for which they are trying to prepare students. In community colleges, the disability resources centers provide 
accommodations and support for students when they arrive at the college. Many community colleges solicit input from high schools and do extensive outreach; nonetheless, a gap still persists when it comes to students accessing the services they need when transitioning from high school to community college.

Students with learning disabilities who seek a job when they graduate from high school have a disproportionately lower educational attainment and more limited employment opportunities than their peers without disabilities, which often leads to higher unemployment rates, placement in lower skilled jobs, lower incomes, and higher rates of poverty (Denhart, 2008). In contrast, students with disabilities who continue their education beyond high school tend to acquire higher-order thinking and technical skills that lead to advanced-level jobs rather than entry-level positions, enabling them to access current globalized job trends (Finn et al., 2008). These trends suggest that learning-disabled students who attend and graduate from college have acquired the higher-order thinking and technical skills needed for meaningful career attainment and are more likely to have access to higher skilled jobs and realize higher incomes.

\section{Rationale for the Study}

Kirst and Venezia (2004) called for a national dialogue on college access that examines the civil rights struggle of how schools support or impede students on their path to postsecondary education. This is particularly true when it comes to how schools support or impede learning-disabled students' transitions from high school to community 
college. There is a very real need to better understand both (a) specific college readiness skills, such as academic behavior, study skills, and personal attitude; and (b) students' awareness of their disability as well as their ability to communicate needs related to their disability affect their first semester in college. Suggesting the existing disproportionate imbalances in educational attainment for this population and the failure to adequately prepare students with learning disabilities to transition from high school to community college is a social justice and equity issue.

The Americans with Disabilities Act (ADA) of 1990, Office of Civil Rights (OCR), and Individuals with Disabilities Education Act (IDEA) are among the key pieces of legislation and organizational structures that protect the civil rights of students with disabilities and ensure equal access to education. The OCR, which includes Section 504 of the Rehabilitation Act of 1973, and Title II of the American with Disabilities Act of 1990 prohibit discrimination against people with disabilities in accessing all public services, including education, employment, transportation, and accommodations in public buildings.

IDEA (2004) specifies that all students with disabilities receive a free, appropriate public education (FAPE) emphasizing special education and related services to meet their unique needs and prepare them for future education, employment, or independent living. This includes transition services through which students with learning disabilities are placed into special education programming. Individualized transition services are 
provided by the time the student is age 15. According to IDEA (SEC 300.43, 2004), transition services refer to a coordinated set of activities for a student with a disability. Transition services include postsecondary education and are based on individual student needs, taking into consideration strengths, preferences, and interests. Students with disabilities are entitled to the same educational rights as students without disabilities and are entitled access to the same education options.

Addressing the transition of students with learning disabilities from high school to community college from a social justice and equity stance, demands educational leaders, teachers and counselors to think anew about the transition, supports they provide to students with learning disabilities as they transition from high school to college. Yet, according to data from the National Longitudinal Transition Study-2 (NLTS-2), transition planning has mostly included school-based personnel and concluded that students were not taking an active role in guiding and leading their transition (Shogren \& Plotner, 2012). This is particularly problematic for students with disabilities as they transition, after having to reach the legal age of adulthood, to college where neither their parents nor the high school team are in a legal position to serve as their advocate. Making the involvement of students with learning disabilities key players in the transition planning is in keeping with Carter et al.'s findings (2006) that successful high school transitions require high school students to assume more prominent roles in education and life planning, including understanding and communicating their strengths and needs, setting 
and working toward self-selected goals, advocating for themselves, and self-assessing their own progress and outcomes. This requires educational leaders to collaborate with school staff, parents, and students to modify the current process for transition planning in special education. Placing the voice of students with learning disabilities in the center of the dialogue on the transition from high school to college is perhaps the most significant justification for this research.

Expanding the knowledge base related to assisting educational leaders in addressing transition as an equity issue is critical for increasing the likelihood that students with learning disabilities transitioning from high school to community college have the same education opportunities available to them as students without disabilities. This access is dependent, however, on students with learning disabilities having a successful transition from high school to community college. From an equity lens, this necessitates the providing of additional assistance to support students with learning disabilities access to the same core programs as their peers without disabilities. Without successful transition planning and support, these students are more likely to drop out of college, which can ultimately lead to low-skilled jobs, unemployment, and conceivably a life of poverty. 


\section{Research Questions}

There is limited research on what best supports a positive transition from high school to the community college system. This study addresses the following research questions:

- What characteristics are essential for students with learning disabilities to successfully transition from high school to college?

- How do college readiness skills, such as academic behaviors, study skills, and personal attitudes, contribute to successful college transitions?

- How do the students' awareness of their disability and their ability to self-advocate to communicate their disability needs affect their first semester in college?

In answering these two questions, both the importance of these characteristics and their contribution to a successful high school to community college transition contribute to literature, which enables practitioners to identify key characteristics of special education transition programs and successful student characteristics that are associated with an effective transition from high school to community college.

\section{Conceptual Framework}

This study is grounded in psychological theories of the Self-Determination Theory (SDT) (Deci \& Ryan, 1985) and addresses the attributes that students need for a 
successful transition from high school to college. This study draws on SDT to understand how successful students with learning disabilities assess their college readiness in terms of academic, study, and self-advocacy skills when transitioning from high school to college.

\section{Key Terms}

Students with disabilities. Students with disabilities are individuals with a physical, medical, cognitive, emotional, behavioral, social, or learning impairment that need an accommodation to perform functions required to carry out life activities (Gabel, 2006).

Learning disability. Learning disability is a disorder in one or more of the basic psychological processes involved in understanding or in using language, spoken or written, which may manifest itself in the imperfect ability to listen, think, speak, read, write, spell, or do mathematical calculations (IDEA, SEC 300.8, 2004).

Transition services. Transition services are a coordinated set of activities for a student with a disability, which includes postsecondary, as well as vocational education, integrated employment (included supported employment), continuing and adult education, adult services, independent living, or community participation (IDEA, SEC $300.43,2004)$. 
College readiness. College readiness is a multi-faceted concept that includes contextual skills and awareness, academic behaviors, key content, and key cognitive strategies that students need for college success (Conley, 2007).

Disability awareness. Disability awareness is the student's own knowledge of their disability, knowledge of their rights and responsibilities, as well as postsecondary school responsibilities regarding accommodations outlined in the American Disabilities Act of 1999 (Milsom \& Dietz, 2009).

Self-advocacy. Self-advocacy involves students possessing an awareness of their needs and the abilities to effectively communicate those needs to others (Milsom \& Hartley, 2005).

\section{Study Procedures}

The study was conducted at a Northern California community college and a comprehensive high school in Northern California. Participants were recruited from the community college by invitation to a voluntary informational meeting at the Disability Student (DS) learning lab at the community college. To recruit participants from the comprehensive high school, former students were contacted and invited to participate in the study. All participants were given a brief description of the purpose of the study and asked to participate. They volunteered their time with no compensation and signed a written consent form. After obtaining consent to participate, the researcher arranged a 50-minute meeting that included completion of a survey and individual interviews. 
This mixed methods study included the ARC Self-Determination Scale (ARC), a standardized instrument to measure aspects of self-determination. It contains 72 questions administered by participant self-reporting. It also consisted of a semistructured interview protocol to explore the characteristics of self-determination during the transition from high school to college. Interviews were transcribed by the researched and coded for thematic analysis. To preserve the anonymity and confidentiality of the participants, no identifying information was used or presented throughout the study. Names were changed and aliases were used.

This study is organized in five chapters. Chapter one describes the purpose of the research, the problem studied, the guiding research questions, and conceptual framework. The chapter also defines relevant terminology. Chapter two reviews the literature on students with learning disabilities and college transition. Chapter three outlines the research methodology used to gather and analyze the data. Chapter four presents the results and findings of the study. Chapter five summarizes the findings, discusses the implications of the study, and offers a perspective on the study. 


\section{Chapter 2: Literature Review}

The central focus of this study was to explore the transition of students with learning disabilities from high school to community college. The literature review presented in this chapter begins with an overview of the literature data and background on transition including college readiness, disability awareness, and self-advocacy skills that are required during the transition from high school to college. This is followed by an introduction of theories of self-determination and how these theories have been used in previous research on transition.

This chapter provides a background on the transition to postsecondary education and how students with learning disabilities require a different set of behaviors and skills to be successful in college. It also introduces theories of self-determination as a framework and explores skills, behaviors, and attitudes that are essential for students with learning disabilities to transition to postsecondary education and navigate through college. Three characteristics that have been found in literature to promote successful transition are college readiness, disability awareness, and self-advocacy. These characteristics, as well as some features of self-determination (e.g., autonomy, competence, relatedness) that foster intrinsic motivation, are predicted to be essential for students with learning disabilities to successfully transition from high school to college. 
To conduct the review of articles, multiple database searches were used including ProQuest Education Journals and ERIC Institute of Educational Services to search for peer-reviewed articles that were focused on education. PsycINFO was used to search for peer-reviewed articles focused on behavioral and social sciences. And lastly, Google Scholar was used to supplement the data queries. Keyword searches included several combinations including: college success and learning disability, college transition and disability, self-determination and disability, college readiness and learning disability.

The initial data queries were done in ProQuest, ERIC, and PsycINFO to narrow the focus of the search, as well as target peer-reviewed journals and articles. These databases provided access to different journals as well as multiple article formats. The number of references also varied depending on the keyword search and the topic specialization of the database. Queries that were completed in ProQuest returned a large selection of articles. Exclusionary factors that were considered when using ProQuest include the type of journal, the relevance to topic of students with learning disabilities transitioning to college, the age of the article, and if the article was peer reviewed. The searched also included published dissertations and other works which were sometimes reviewed for additional references but not used in the literature review for this study.

\begin{tabular}{|l|r|r|r|}
\hline & ProQuest & ERIC & PsycINFO \\
\hline College success \& Learning disability & 24,300 & 6 & 17 \\
\hline College transition \& Learning disability & 14,400 & 3 & 17 \\
\hline
\end{tabular}




\begin{tabular}{|l|r|r|r|}
\hline College readiness \& Learning disability & 6,900 & 17 & 8 \\
\hline Self-determination \& Learning disability & 4,000 & 607 & 968 \\
\hline
\end{tabular}

After a review of multiple articles, a pattern of authors and researchers were noted in many of the articles. A selection of authors was used to query additional articles. Some of those keyword (author) searches were "Wehmeyer," "Morningstar," and "Troiano." These queries were often conducted by using Google Scholar and a general internet search.

\section{Transition}

The lack of attention to the transition from high school to college is a significant theme in the literature. According to Venezia and Jaeger (2013), "The vast majority of high school students aspire to some kind of postsecondary education, yet far too many of them enter college without the basic content knowledge, skills, or habits of mind they need to succeed." It is therefore no great surprise that too many learning-disabled students enter college unprepared for its academic demands and so require programs that not only address the basic academic skills needed for college-level courses, but also instill the behavior that will make them successful in college (Grubb \& Gabriner, 2013). Addressing these inadequacies calls for a change in how students with learning disabilities are prepared for the transition from high school to college to address three 
characteristics consistently found in the literature: college readiness, disability awareness, and self-advocacy.

Much research has been focused on transition planning and teaching selfdetermination as part of the transition curriculum in high school. Assessment interventions as suggested by Field and Hoffman (2007) include standardized instruments such as the ARC Self-Determination Scale, AIR Self-Determination Scale, ChoiceMaker Self-Determination Assessment, Self-Determination Assessment Battery, and curriculumbased assessment tools. Self-determination can be promoted in transition assessment by encouraging students to be involved in organizing the assessment data, presenting the data, as well as being involved in the transition planning meetings (Field \& Hoffman, 2007).

College readiness. Although college readiness is typically defined for general education students in terms of high school courses taken, grades received, and scores on standardized testing, students with disabilities face a range of additional challenges in adjusting to postsecondary school and tend to be less academically prepared than their general education peers (Lombardi et al., 2012). David Conley (2007) redefined college readiness as "the level of preparation a student needs in order to enroll and succeed without remediation in a credit-bearing general education course at a postsecondary institution." A student that is college ready should be able to understand course expectations, understand the content knowledge, take away key concepts from the course, 
and be prepared to understand college culture and structure and comply to intellectual norms of the academic and social environment (Conley, 2007).

Students with learning disabilities who matriculate in higher education are reported to work through problems at an extremely slow pace and have trouble retaining simple information or directions (Grubb \& Gabriner 2013). They also may need to be able to recognize their academic struggles and act more proactively to address their needs by requesting accommodations and accessing study resources at their college. This is because higher education is not configured in the same way as the P-12 system to address the needs of students with disabilities.

The National Council on Disability (2003) reports that students with disabilities are behind their peers in academic preparedness. They are often not appropriately advised to take classes that meet college entrance requirements and may not receive the support and accommodations that they need. Findings from the National Longitudinal Transition Study-2 (NLTS2) indicate that $35 \%$ of secondary students with learning disabilities received the general education curriculum used in academic classes and that only $52 \%$ of them received the necessary modifications to help them succeed in the general education classes (Garrison-Wade \& Lehmann, 2009).

The demands of college, including autonomy, self-monitoring, and problem solving, require students to adjust to multiple settings and task demands. The development of strategies to enhance these skills can be particularly important for helping 
students with learning disabilities succeed (Ruban et al., 2003). In a university study of the Self-Determined Learning Model of Instruction (SDLMI), participants commented on how the problem-solving processes of self-monitoring, self-discipline, and selfdetermination were needed to be successful in college (Finn et al., 2008).

Academic behavior and study skills are also important facets of college readiness. For students with learning disabilities, this should include important academic abilities and personal attitudes for college success, as well as assessments of self-awareness, academic preparedness, social supports, and personal responsibility (Milsom \& Dietz, 2009). In an academic self-regulation study (Ruban et al., 2003), the needs of students with learning disabilities differed significantly from students without disabilities. This study consisted of learning strategies and a study skills survey that measured students' perceptions of usefulness and their use of self-regulated learning and study strategies. Students with learning disabilities lacked academic self-regulation and were reported to work harder to develop an effective reading system, take good notes, organize their study time, manage their academic assignments, and approach test-taking situations effectively (Ruban et al., 2003). These study skills as well as preparation in academic subjects are clearly important in college success.

Disability awareness. Another characteristic identified as important for the college success of students with learning disabilities is disability awareness. It includes knowledge of one's own disability, rights and responsibilities, and postsecondary school 
responsibilities regarding accommodations outlined in the ADA (Milsom \& Dietz, 2009). Students with learning disabilities are not effective self-advocates if they do not understand how they learn or have knowledge of their legal rights and responsibilities (Garrison-Wade \& Lehmann, 2009). After students gain enough knowledge about their disability and its relationship to their social and academic environment, students can begin to establish goals and achieve them independently (Schutz, 2002).

According to Janiga and Costenbader's (2002) research on college service coordinators, high school transition teams need to provide students with an understanding of their own strengths and weaknesses and the specific accommodations they need (Janiga \& Costenbader, 2002). High school students with learning disabilities transitioning to college must develop specific competencies, respond appropriately to their new environment, and develop independence (Hadley, 2006).

This self-knowledge, as evaluated in a Delphi study by Milsom \& Dietz (2009), is one of the most important characteristics of college readiness. It includes the knowledge of personal strengths and weaknesses as well as knowledge of available accommodations that colleges offer to address their learning needs. In a study by Skinner (2004), college students with learning disabilities were interviewed about what it took for them to be successful in college. Eight themes were identified, but the top theme was "knowledge of disability and concomitant accommodations." Skinner (2004) concluded that students 
who lack knowledge of their disability and accommodations as well as awareness of their strengths and weaknesses are more likely to experience academic failure.

In a study of academic identity development for college students with learning disabilities, self-determination and GPA were examined. Anctil et al. (2008) identified persistence, competence, career decision-making, and self-realization as outcomes of self-determination. One conclusion suggested that persistence enhances competence. Many of the study participants shared how their negative experiences and academic difficulties were instrumental in their drive to succeed (Anctil et al., 2008).

By learning about their disabilities, including associated strengths and deficits as well as successful interventions and accommodations, students with learning disabilities can be better prepared to set realistic future goals (Milsom \& Hartley, 2005). They should not only understand their disabilities, but also be prepared to make choices and engage in activities that are in their own best interest (Schutz, 2002). Awareness of strengths and weaknesses, the ability to express this awareness to college faculty, awareness of the service needs and appropriate accommodations, and the ability to request information, assistance, and accommodations when appropriate are all components of disability awareness (Schutz, 2002). Having this information can assist students in knowing what to advocate for when they are in college. Without a clear knowledge of oneself and one's strengths, needs, preferences, and interests, in addition to the ability to advocate for their needs, students may not have access to the supports 
entitled to them by law (Kochhar-Bryant, Bassett, \& Webb, 2009). Students who have successfully transitioned to higher education programs exhibit an awareness of their strengths and weaknesses, the ability to discuss their accommodation needs with faculty and staff, knowledge about services and supports available to them, and the capacity to access information, services, and support when needed (Finn et al., 2008).

Self-advocacy. Self-advocacy is a key characteristic that students with learning disabilities present when transitioning successfully to college. Self-advocacy involves possessing an awareness of needs and the ability to communicate those needs to others (Milsom \& Hartley, 2005). Students with learning disabilities who do not self-advocate have a difficult time adjusting to college life (Hadley, 2006).

Prior to college, students with learning disabilities are used to family members and teachers advocating for their disability, but in college they are on their own and must advocate for themselves (Patrick \& Wessel, 2013). While high school teachers, staff, and parents share the responsibility of advocating for high school students, their actions depend on the students' initiative (Garrison-Wade \& Lehmann, 2009). At the postsecondary level, in contrast, students must become self-advocates, since nearly all of the responsibility for initiating services is transferred from the school and parent to individual students (Patrick \& Wessel, 2013). Their ability to be assertive in college will greatly aid them in accessing services and discussing their needs (Garrison-Wade \& Lehmann, 2009). 
Self-advocacy also includes knowledge of the importance of support systems (Skinner, 2004). These relationships contribute to the relatedness of self-determination and may include peers, faculty, family, and academic resource supports. In the study of motivational models by Guiffrida, Lynch, Wall, and Abel (2013), relatedness was also studied as a subset and how fulfilling relatedness needs by building relationships with college faculty and staff was positively associated with higher GPAs and academic outcomes (Guiffrida et al., 2013). Students who connect with faculty and staff and advocate their needs are more likely to establish and benefit from these relationships (Guiffrida et al., 2013).

The importance of self-advocacy is also identified in Skinner's (2004) study of college students with learning disabilities. Students should be aware of their legal rights and be able to communicate their rights and needs to their college faculty, as well as be able to express confidence in approaching instructors to request appropriate accommodations related to their learning disability (Skinner, 2004). Morningstar et al. (2010) calls this self-determined confidence "psychological empowerment." This type of empowerment can help students become better advocates, which can lead to more successful postsecondary outcomes.

\section{Self-Determination Theory}

Self-determination theory offers a framework for understanding the strengths and weaknesses associated with students who have learning disabilities. It provides 
advocates, educators, and policy makers a schema within which they can foster the development of self-determination of students with disabilities from school age to college levels (Anctil et al., 2008). A corollary of self-determination theory, the self-determined learning model of instruction, is also discussed in the review. Prior research further suggests that three key features contribute to successful transition for students with learning disabilities: college readiness, disability awareness, and self-advocacy. Using self-determination theory, this study will explore these characteristics of transition in detail.

In the literature, self-determination refers to having the ability, motivation, and supports needed to direct one's life in ways that are meaningful (Carter et al., 2006). It is the ability to know oneself and one's environment and use this foundation to identify and obtain goals (Field \& Hoffman, 2007). Self-determination and student involvement in educational programming promote similar access to education for students with disabilities as their general education peers and bridge the relationship between general and special education staff. For the purposes of this study, the construct of selfdetermination offers a framework for understanding the specific strengths and weaknesses associated with positive outcomes of students with learning disabilities.

Deci and Ryan's self-determination theory (SDT) is a general theory of human motivation concerned with the development and functioning of personality within the social context (Deci \& Chandler, 2001). It is a theory of intrinsic motivation with three 
features that foster intrinsic motivation, including autonomy, competence, and relatedness. Autonomy develops when students choose to become engaged in learning because the subject and activities are closely aligned with their interest and values (Guiffrida et al., 2013). Competence is the need to test and challenge one's abilities (Guiffrida et al., 2013) and the innate need to feel effective or competent in managing their environment (Deci et al., 1991). Relatedness is the need to establish close, secure relationships with others.

Previous research on SDT and transition has been conducted on persistence and retention in college; however, limited research has been done for students with learning disabilities. Guiffrida et al. (2013) explored motivational models of college students in their reasons for attending college and their academic outcomes. This study used three instruments to measure motivation, persistence, and autonomy: questionnaire used to assess patterns in GPA, a student's intent to persist in college, and reasons for attending college from an SDT perspective.

Using SDT as a theory of motivation and another theory highlighting student persistence, Guiffrida et al. (2013) determined that autonomy and competence were positively associated with a student's intent to persist in college and their GPA. The highest correlation was between competence and intent to persist at .29. Also when looking at SES, autonomy and GPA were more positive with students from a high SES 
than students from a low SES. The standardized coefficient from lower SES was only .159 , and .220 for students with higher SES backgrounds.

Several self-determination scales have been developed to explore selfdetermination in students at all levels and within different abilities and disabilities. The most widely used are the AIR Self-Determination Scales (1994) and the ARC SelfDetermination Scale (1995).

The American Institutes for Research (AIR) in collaboration with Teachers College, Colombia University (Wolman et al., 1994) developed the AIR SelfDetermination Scales. The AIR Self-Determination Scales are used with students of all ages ranging from kindergarten until 21 years old. The focus of this scale is based on a two-factor capacity, referring to a student's knowledge, abilities, and perceptions that enable them to be self-determined, and opportunity, which refers to the occasions a student has to use the knowledge and abilities they possess.

In a research study by Carter, Trainor, Owens, Sweden, and Sun (2010), students and teachers completed the AIR Self-Determination Scales to determine how teachers evaluate the self-determination capacities and opportunities of youth, to what extent social skills and problem behaviors are associated with the capacity and opportunities students have to engage in self-determined behavior, and if teacher and students share the same perspectives of capacities and opportunities in self-determination. These include 
students with learning disabilities, emotional behavioral disorders, and mild/moderate cognitive disabilities.

The results of the AIR Scales indicated that students with emotional and behavioral disorders and students with cognitive disabilities were perceived to have low prospects of self-determination (Carter et al., 2010). The perceptions of students with learning disabilities and the perceptions of teachers were correlated at .34, while they correlated at .07 for cognitive disabilities and .02 for emotional and behavioral disabilities. These particular perceptions of educators are of significance because students with learning disabilities are perceived more capable than students with other disabilities. In the study, teachers reported their perception that students with learning disabilities have a greater capacity for self-determination and have more opportunities available to them regardless of their disability (Carter et al. 2010).

The ARC Self-Determination Scale was developed by Michael L. Wehmeyer, Ph.D. (1995), following an evaluation of self-determination of more than 400 adults with developmental disabilities. It is based on self-determination as a "primary causal agent in one's life and making choices and decisions regarding one's quality of life free from undue external influence or interference" (Wehmeyer, 1995). The ARC Scale measures the four essential characteristics, including autonomous behavior, self-regulated behavior, psychological empowerment, and self-realization. 
The ARC Self-Determination Scale has been used in studies measuring student involvement in transition planning (Wehmeyer et al., 2007), technology usage in transition planning (Wehmeyer et al., 2011), and the success outcomes of two-year college students with disabilities (Jameson, 2007). In Wehmeyer's study measuring student involvement in transition planning, the ARC survey was used to gather data on self-determination of 180 high school students receiving special education. This data was used in conjunction with a questionnaire designed to measure transition knowledge and skills. The study examined the relationship between student transition planning knowledge and skills to essential characteristic of self-determination. Of the 180 participants, 93\% reported that they had attended their transition meetings; however, only $63 \%$ knew of their transition goals. Some of the predictors to student involvement in their transition planning included higher scores $(r=.546)$ in self-regulated behavior on the ARC Self-Determination Scale.

Wehmeyer's study on technology use in transition planning, the ARC Scale was used to measure the level of self-determination after two groups of high school students with disabilities received instruction in transition planning. One group received instruction and support on transition planning from a cognitively accessible computer software program, and another group received transition planning support and instruction without technology. This study also utilized the AIR Self-Determination Scale, as well as a Transition Empowerment Scale. The results of this study did not suggest that 
technology use had a significant effect on the students' self-determination, as measured by all three scales (Wehmeyer et al., 2011).

The ARC Self-Determination Scale was also used in Jameson's (2007) study on success outcomes of two-year college students with disabilities. The goal of this study was to investigate transition programs and support that result in successful outcomes for two-year college students with disabilities and determine whether self-determination may be linked to positive success outcomes (Jameson, 2007). It was sequential mixed method research designed so that it utilized the ARC Scale in the first phase of quantitative data collection, as well as a demographic and outcomes survey. The second phase was a follow-up interview that occurred shortly after the completion of the surveys. Three areas that the questions focused on were life history, details of their postsecondary experience, and a reflection on where they are as a college student with a disability.

The self-determined learning model of instruction (SDLMI), a corollary of selfdetermination theory, is a model of teaching that is designed to promote selfdetermination and support student self-regulated problem-solving and self-direction in learning (Wehmeyer et al., 2012). It is reported that this teaching design assists students with disabilities to understand the skills needed in postsecondary education, identify and overcome barriers, and self-monitor their progress (Finn et al., 2008). SDLMI has been used in studies of academic and career development, self-determination, student involvement, and access and goal attainment. Shogren and Plotter (2012) linked the 
SDLMI to student access to general education curriculum and their attainment of academic and transition-related goals. For students with learning disabilities in college, there was higher academic goal attainment after one year of SDLMI (Shogren \& Plotter, 2012).

Using SDLMI, college students with learning disabilities, in a study by Finn et al. (2008), were taught a three-step problem solving process that included setting a goal, taking action, and adjusting goals and plans. The students reported greater confidence in approaching professors to discuss their accommodations, and over two thirds of the participants indicated a positive change in this area (Finn et al., 2008). They had a greater comfort level in explaining and describing their disabilities and $40 \%$ greater acceptance of their disabilities. Using models of self-determination to develop skills in college readiness, disability awareness, and self-advocacy, students with learning disabilities were able to understand the skills needed in postsecondary education and monitor their progress to overcome obstacles and barriers in college.

\section{Summary}

Increasing self-determination in the transition process thus has the potential to address the improvement of postsecondary educational outcomes (Morningstar et al., 2010). According to the literature review, the characteristics that have been beneficial to success in high school to college transitions are characteristics of self-determination, as well as support from high school and college programs. Using theories of self- 
determination, this study explores how students are prepared for college in high school, how much knowledge they have about their disability, how these students utilize their strengths and seek help to support their weaknesses, and how these characteristics impact and contribute to their college success. 


\section{Chapter 3: Research Design and Methodology}

The research and design methodology for this mixed methods study is presented in this chapter in two main sections: (a) an overview of the design and the research questions, and (b) the methodology section, which describes participation and analysis.

\section{Overview}

The purpose of the study was to learn more about how students with learning disabilities navigate through the community college system during their first year as a college student. Of particular interest was to better understand how college readiness, disability awareness, and self-advocacy skills impact the way students with learning disabilities transition from high school to college.

In this mixed methods study, the researcher evaluated how students with learning disabilities perceived and talked about how they navigated through the community college system during their years as a community college student, with a particular interest on the first year attending community college. Exploring how college readiness, disability awareness, and self-advocacy skills impact the way students with learning disabilities transitioned from high school to college. This mixed-methods study employed Self-Determination Theory (SDT) as the analytical framework to evaluate student perceptions of their college readiness, disability awareness, and self-advocacy skills, as well as how these characteristics impacted and contributed to their school 
success. The quantitative portion of this study utilized the ARC Self-Determination Scale (ARC) and compared levels of self-determination to the success that a college student with learning disabilities had in the first semester of college. Transcripts and grade point average (GPA) were used to both measure and compare college success and self-determination levels.

In the qualitative portion of this study, community college students with learning disabilities participated in an interview about their perceptions of their transition from high school to college. This study can help researchers gain an understanding of how students with learning disabilities perceive their readiness for college, awareness of their disabilities, and how high school programs can better prepare students for college. Using a convergent design enabled the researcher to frame the collection and analysis of data to gain an understanding of how these students with learning disabilities perceived their readiness for college, awareness of their disabilities, and how high school programs prepared and did not prepared them for community college.

\section{Rationale for a Mixed Method Design}

The purpose for a mixed-methods study is to explore the characteristics that contribute to a successful from high school to community college for students with a learning disability. The researcher conducted a mixed methods convergent parallel research study, because it was most appropriate to the goal of exploring how selfdetermination characteristics as measured by a self-determination scale contribute to a 
successful college transition and how other characteristics contribute or influence students with learning disabilities as they transition from high school to college. Through the use of a convergent design that incorporated quantitative data gathered and qualitative data through triangulating the quantitative findings with the qualitative findings (Creswell and Plano-Clark, 2011). In this study the quantitative data was obtained through administering the ARC Self-Determination Scale (ARC), and the qualitative data was collected through the use of a semi-structured interview protocol.

The research collection was conducted in the February and March of 2016, during spring quarter or semester. It was conducted in the spring to allow first year students to have a community college experience before participating in the study. It included a review of the student's unofficial transcript, quantitative data collected by the ARC SelfDetermination Scale (ARC), and qualitative data collected through the use of a semistructured interview protocol. The students provided their unofficial transcript at their scheduled interview and survey completion meeting.

\section{Research Questions}

The following questions were used to guide the study and determine what characteristics are essential for students with learning disabilities to successfully transition from high school to college: 
- How do college readiness skills such as academic behavior, study skills, and personal attitudes contribute to successful college transition?

- How do the students' awareness of their disability and their ability to self-advocate to communicate their disability needs affect their first semester in college?

\section{Target Population and Participants}

The study consisted of first year community college students with learning disabilities. Purposeful sampling was used because the use of a random sample was not appropriate, desirable, or feasible from a methodological or practical perspective. In this study, the students with a learning disability transitioning to community college were the target population, while the individual participants of the study met the sampling criteria. The study participants were an accessible population because they met the established criteria and were accessible in terms of researcher availability, time and funding. For this study the established criterion involved the identification of students with a learning disability transitioning from high school to community college while the criterion for accessibility centered on geographic proximity of the students to the researcher. The accessible sample attended community college in the Greater San Francisco Bay Area. The accessible subject population for this study was composed of a set of [number] students with a learning disability transitioning to community college. Participants in the 
study included college students at Pacific Community College, a Northern California community college, as well as participants who have recently graduated from Southeast High School, a Northern California comprehensive high school. The researcher was a district school psychologist. Many former students return to the high school to visit the researcher and other school staff.

To recruit students from the community college, students who accessed the Disability Student (DS) services and programs and used the college learning-lab were invited to a voluntary informational meeting about the research study. Students were invited by an invitation flyer posted around the DS program or given to them in their learning skills courses. In addition, the researcher contacted former Southeast High School students and invited them to participate in the study.

Participants who were recruited from the community college were invited to an informational meeting at the DS program office. Although the participants did not know the researcher, many of the participants knew another member of the dissertation committee who worked in the DS program office. These participants were informed about the research and were asked to voluntarily participate in the study. After obtaining consent to participate, the researcher arranged 50-minute meetings that included an individual interview and the completion of the ARC Scale (Survey). 


\section{Informed Consent}

As part of the recruitment process all participants were provided a brief description explained the study, the needed commitment, and asked to participate. Participants volunteered their time with no compensation and signed a written consent form (Appendix A). All participants were given an option to leave the study at any time. To preserve the anonymity and confidentiality, no identifying information was used or presented throughout the study. All surveys, transcripts, audio recordings, and transcriptions were kept on the researcher's password protected computer.

\section{Instrumentation (Survey and Interview Protocol)}

The quantitative instrument used in this study was the ARC Self-Determination Scale. It was chosen because it is a student self-report survey. A total measure of selfdetermination is calculated; however, this scale is also divided into subscales of autonomy, self-regulation, psychological empowerment, and self-realization. The subscales are useful in identifying particular characteristics that are essential in the transition of students with learning disabilities from high school to college. The AIR Self-Determination Scale was also considered, but the surveys include parent, educator, and student self-report surveys. Because this research study is based on the student selfperception, the ARC was more relevant to this study.

$\mathrm{ARC}$ is used to measure characteristic of self-determined behavior: autonomy, self-regulation, psychological empowerment, and self-realization, particularly with 
students with mild mental retardation and learning disabilities. This instrument contains 72 questions and is administered by student self-reporting. It evaluates four essential characteristics: (a) the individual acts autonomously; (b) if the behaviors are selfregulated; (c) if the person initiates and responds to event(s) in a "psychologically empowered" manner; and (d) if the person acts in a self-realizing manner (Wehmeyer, 1995)

Success, or a successful transition, was based on the students' performance on the courses that they attended during their first semester of college. Transcript grades and grade point average were used to measure their performance. This data was used in comparison with the results of the ARC Scale. The results were correlated to determine if self-determination and characteristics of self-determination affect the academic performance of students with learning disabilities transitioning to college.

The qualitative data for this study was obtained from a semi-structured interview protocol developed to explore characteristics of self-determination in the transition process from high school to college as well as gather information on their prior expectations of college, their actual experiences, and ideas about how they think the transition process could be improved. Additional questions addressed the students' experiences in their first semester of college and how social views of disability impacted their experience. The interviews were transcribed by the researcher and coded for thematic analysis. 


\section{The ARC Scale Surveys (Quantitative Instrument)}

The study used an existing instrument that has been used with students and validated in other research studies (Wehmeyer, 1995). The ARC Scale was constructed in such a manner to limit problems with reliability and validity. However, it should be recognized that it provides an indication of students' perceptions of their selfdetermination. As the definitional framework upon which this assessment is based proposes, individual perceptions are critical aspects of becoming self-determined. Students can possess all the skills necessary to be self-determined, but if they are never allowed to employ these skills, may grow to believe that they are not capable. Thus, student perceptions become a particularly important aspect to understand when trying to promote self-determination (Wehmeyer, 1995).

In this study the self-perception survey was used to measure students' selfperceptions of their disability knowledge, self-determination, how they accessed services in their community college institutions, and to evaluate and identify what skills impacted and contributed to their success in college. To show the progress and success, the students shared their grades after their first semester in college. One limitation of the study was that generalizability might be unwarranted because the participants were from a particular regional area, Northern California, and only a small subset of the population was being studied. 
After data was collected, the ARC Scale surveys were hand-scored by the researcher and recorded onto a data spreadsheet. The spreadsheet included the total selfdetermination score, as well as the four scales, autonomy (and subscales), self-regulation (and subscales), psychological empowerment, and self-realization.

\begin{tabular}{|l|l|l|l|}
\hline & Student 1 & Student 2 & Student 3 \\
\hline AUTONOMY & & & \\
\hline $\begin{array}{l}\text { Independence: Routine personal care and } \\
\text { family oriented functions }\end{array}$ & & & \\
\hline $\begin{array}{l}\text { Independence: Interaction with the } \\
\text { environment }\end{array}$ & & & \\
\hline $\begin{array}{l}\text { Preferences, beliefs, \& interests: } \\
\text { Recreation and Leisure }\end{array}$ & & & \\
\hline $\begin{array}{l}\text { Preferences, beliefs, \& interests: } \\
\text { Community Involvement }\end{array}$ & & & \\
\hline $\begin{array}{l}\text { Preferences, beliefs, \& interests: Post- } \\
\text { School directions }\end{array}$ & & & \\
\hline $\begin{array}{l}\text { Preferences, beliefs, \& interests: Personal } \\
\text { Expression }\end{array}$ & & & \\
\hline SELF-REGULATION & & & \\
\hline $\begin{array}{l}\text { Interpersonal cognitive problem-solving } \\
\text { Goal setting and task performance }\end{array}$ & & & \\
\hline
\end{tabular}




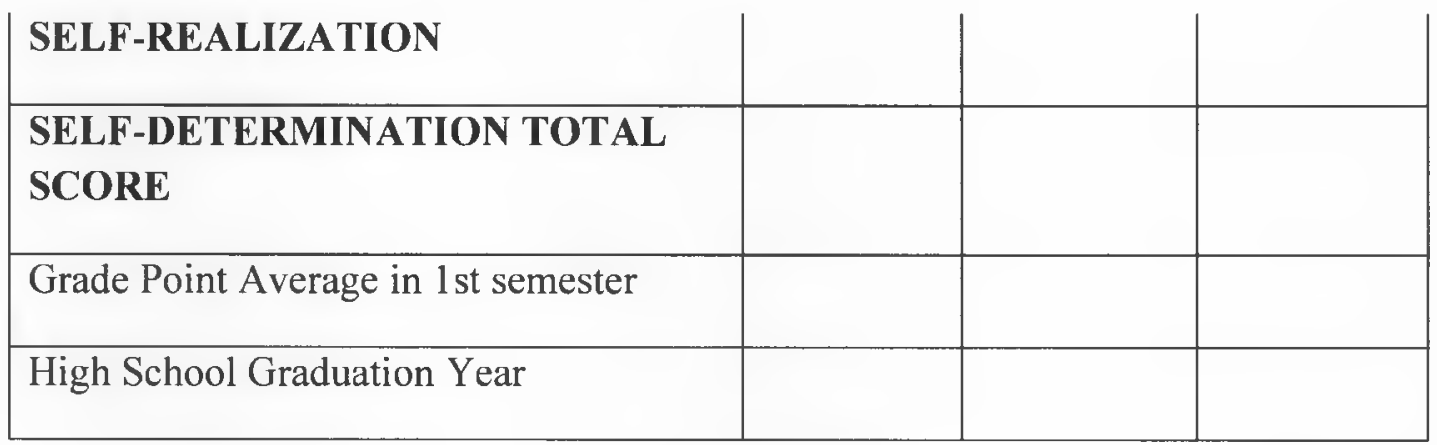

Each student's grade point average and high school graduation year were also included on the table. Descriptive statistics were used to analyze the data. The research used correlational evidence to determine if particular self-determination characteristics impacted academic performance.

\section{Qualitative Instrumentation (Interview Protocol)}

The interview process involved a semi-structured interview (See Appendix C). The semi-structured interview was designed with the intent of gathering data from community college students with learning disabilities about their transition from high school to the community college. In these interviews, topics and questions were presented to the participant with the intent to draw out her or his thoughts about their high school preparation, transition to college, and how they could have been better prepared.

\section{Data Analysis}

All face-to-face interviews were recorded live and transcribed verbatim. For all of the transcripts an in-depth content analysis was conducted using thematic coding techniques. First and second round data coding was used to organize the data to identify 
common themes. These themes were used to help understand what is needed in programs to support students with learning disabilities transition to college.

During the first round of coding, the researcher prepared the data by using a descriptive coding approach. This allowed the researcher to assign labels to the data by summarizing in one word or short phrase the basic topic of the passage of the qualitative data (Miles, Huberman, \& Saldana, 2014). The researcher assigned rough descriptions without judgment or pre-determined categorizations. After all of the qualitative data was labeled, the researcher reviewed the data again and used a holistic coding approach to capture a sense of the overall contents and determine possible categories that developed (Miles, Huberman, \& Saldana, 2014).

The second round of coding identified general content and category labels such as characteristics (CHAR), challenges (CHAL), strengths (STREN), preparedness for college (PREP), high school knowledge (HS), disability programs (DPS), disability awareness (AWARE), communication to professors (COMM), accommodations (ACCM), impact of accommodations (IMP), social perception (PERC), advice to high school students (ADV2STUD), and advice to high school teachers (ADV2TEA). Using a second round of coding clustered the data into categories, themes, and constructs (Miles et al., 2014).

After analyzing quantitative and qualitative data individually, the data was evaluated for triangulation. Triangulation seeks to converge, corroborate, and correspond 
research results from qualitative and quantitative methods (Greene, Caracelli, \& Graham, 1989). Data was collected concurrently to compare and search for congruent findings. Using complementary methods to examine the qualitative and quantitative data, the data analysis sought to elaborate, enhance, illustrate, and clarify the results from one method with the results from the other method (Greene et al., 1989). 


\section{Chapter 4: Report of Findings}

"In high school, most of the teachers are like they go towards you and ask you if need any help but in college, it's mostly like you have to go and ask them. You have to schedule your own appointments, to talk to your professor, and get the help that you need." (Interview: 2/9/2016) - Judy

The purpose of this mixed method study was to develop an understanding of how students with learning disabilities perceived their transition from high school to community college. This chapter is the beginning of the story about the transition from high school to community college based on both qualitative and quantitative data reflecting the voices of 14 students with learning disabilities. The names of the students have been changed to protect their confidentiality.

Ten students from Southeast High School, a Northern California high school in a suburb of San Jose, California participated in the study. Eight students were from the graduating class of 2015, while two students were from the class of 2013 . They attended four different community colleges in the grater SF South Bay. Four of the students who participated were from Pacific Community College, a Northern California community college in a suburb of San Francisco, California. These students attended different high schools and represent graduating in either 2013 or 2014. 


\begin{tabular}{|c|c|c|c|c|}
\hline Participant & $\begin{array}{l}\text { High School } \\
\text { Graduation }\end{array}$ & $\begin{array}{l}\text { Semesters } \\
\text { in College }\end{array}$ & High School & Community College \\
\hline Jeremy & 2015 & 0 & $\begin{array}{c}\text { Southeast } \\
\text { High School }\end{array}$ & $\begin{array}{l}\text { Main Community } \\
\text { College }\end{array}$ \\
\hline Anna & 2013 & 1 & $\begin{array}{c}\text { Southeast } \\
\text { High School }\end{array}$ & $\begin{array}{l}\text { Main Community } \\
\text { College }\end{array}$ \\
\hline Jasmine & 2013 & 6 & $\begin{array}{c}\text { Southeast } \\
\text { High School }\end{array}$ & $\begin{array}{l}\text { Main Community } \\
\text { College }\end{array}$ \\
\hline Candace & 2015 & 1 & $\begin{array}{c}\text { Southeast } \\
\text { High School }\end{array}$ & $\begin{array}{c}\text { East Bay Community } \\
\text { College }\end{array}$ \\
\hline Priscilla & 2015 & 1 & $\begin{array}{c}\text { Southeast } \\
\text { High School }\end{array}$ & $\begin{array}{c}\text { South Bay } \\
\text { Community College }\end{array}$ \\
\hline Gayle & 2015 & 1 & $\begin{array}{c}\text { Southeast } \\
\text { High School }\end{array}$ & $\begin{array}{l}\text { Main Community } \\
\text { College }\end{array}$ \\
\hline Judy & 2015 & 1 & $\begin{array}{c}\text { Southeast } \\
\text { High School }\end{array}$ & $\begin{array}{c}\text { Western Community } \\
\text { College }\end{array}$ \\
\hline Brian & 2015 & 1 & $\begin{array}{c}\text { Southeast } \\
\text { High School }\end{array}$ & $\begin{array}{l}\text { Main Community } \\
\text { College }\end{array}$ \\
\hline James & 2015 & 1 & $\begin{array}{c}\text { Southeast } \\
\text { High School }\end{array}$ & $\begin{array}{l}\text { Main Community } \\
\text { College }\end{array}$ \\
\hline Jessica & 2015 & 1 & $\begin{array}{c}\text { Southeast } \\
\text { High School }\end{array}$ & $\begin{array}{c}\text { Western Community } \\
\text { College }\end{array}$ \\
\hline Fred & 2014 & 3 & $\begin{array}{l}\text { Urban } \\
\text { Charter }\end{array}$ & $\begin{array}{l}\text { Pacific Community } \\
\text { College }\end{array}$ \\
\hline Mary & 2013 & 6 & $\begin{array}{l}\text { Private } \\
\text { School }\end{array}$ & $\begin{array}{c}\text { Pacific Community } \\
\text { College }\end{array}$ \\
\hline
\end{tabular}




\begin{tabular}{|c|c|c|c|c|}
\hline Penny & 2013 & 6 & $\begin{array}{c}\text { Peninsula } \\
\text { High School }\end{array}$ & $\begin{array}{c}\text { Pacific Community } \\
\text { College }\end{array}$ \\
\hline Megan & 2014 & 4 & $\begin{array}{c}\text { SB High } \\
\text { School }\end{array}$ & $\begin{array}{c}\text { Pacific Community } \\
\text { College }\end{array}$ \\
\hline
\end{tabular}

This is a story of students with learning disabilities transitioning from high school to community college and just how challenging the transition was for these students. All of the participants had different experiences regardless if they came from the same high school or attended the same community college, making it clear that students with learning disabilities not only felt unprepared to transition from high school to community college, but also that they were not receiving the support they needed and are entitled to in order to be successful. Each student is introduced as a prelude to the data analysis.

\section{Southeast High School}

Jeremy, a male student of Filipino descent, graduated from Southeast High School in 2015 and was attending Main Community College as a first semester student when he participated in this study. Jeremy started community college during the spring semester and did not attend college during the fall as a business major. Jeremy registered for DS services when he went to the DS orientation at the beginning of the semester. He felt ready to go back to school after working two jobs after high school. Jeremy was a visual and hands-on learner with auditory challenges. In his first semester, general course accommodations included extra time on tests and taking tests at the DS office. Jeremy 
took one English class that was a DS class so he did not receive any additional accommodations in that course.

Anna, a female student of Pakistani descent, graduated from Southeast High School in 2013 and was attending Main Community College. Anna was making her second attempt at community college after she had dropped out one an a half years ago. During her first semester, Anna did not receive any accommodations from DS services and she did not do well in her classes. She ended up dropping out of college with little intent of returning. After working for the past year, Anna realized that she wanted a college degree so she decided to try again. She was majoring in business entrepreneurship and registered for DS services. However, her meeting appointment did not happen prior to participation in this study.

Jasmine, a female student of Latin descent, graduated from Southeast High School in 2013 and was majoring in sociology at Main Community College. Jasmine was in her sixth semester at the community college. After finishing the semester, she planned on going into the Peace Corps for a couple of years before transferring to a fouryear university. Jasmine attended community college following high school graduation but she did not register for any DS services. She struggled during her first semester until she became active in Puente Project, a program designed to support underrepresented minorities in college. Jasmine became focused on school, participated in clubs and student organizations, and registered for disability services programming. Her 
accommodations included double time testing, a note taker, text-to-speech software, and she also met with her instructors regularly during their office hours.

Candace, a female student of Vietnamese descent at East Bay College graduated from Southeast High School in 2015 and was majoring in theater. She did not register for DS services until the middle of her first semester. Her father was adamant that Candace not "take the easy way out" and did not want her to register with DS services. When her English professor noticed that Candace was struggling, she spoke to Candace about her academic difficulties. After sharing that she had an IEP in high school, the professors referred Candace to DS services at the college. Candace registered for services without informing her father. She felt she was an adult and was in control of her future. Her accommodations included extra time on testing and additional help with essay writing.

Priscilla, an African American female student from South Bay Community College graduated from Southeast High School in 2015 and was majoring in kinesiology. She received a lot of support during her transition to community college because she met with her high school counselor, a transition specialist, and community college counselor before she registered for her classes. Priscilla made an appointment with DS services immediately after she was admitted to South Bay Community College and before her high school graduation. She was well informed and felt very prepared for college. Her accommodations include testing in a quiet room, extra time on tests, and use of audio text. 
Gayle, a female student of Filipino descent at Main Community College graduated from Southeast High School in in 2015 and was majoring in kinesiology. She registered for DS services before she registered for classes. Gayle appeared uneasy and uncomfortable about receiving accommodations and support in the classroom even though she was entitled to them and it is written in her education plan. She shared that she registered with disability services and programming because she only wanted priority registration and she wanted help with class scheduling.

Judy, a female student of Latin descent at Western Community College graduated from Southeast High School in 2015 and was majoring in physical therapy. She registered with DS services and programming prior to starting her first semester. Judy received accommodations to support her math class (e.g. extra time on tests and use of a calculator). One of her strengths was asking for help and not being shy about it.

Brian, a male student of Filipino descent at Main Community College graduated from Southeast High School in 2015 and was majoring in graphic design. He registered with DS services during his last semester in high school prior to graduation. Brian felt prepared for college, about "50/50." During his transition to community college, he received a lot of help from his older sister who also attends Main Community College. Brian struggles with pushing himself to the limit, doing his homework every night, and working hard. His accommodations include a note taker in his classes, extra time on tests, and a quiet location to work. 
James, a male student of Chinese descent at Main Community College graduated from Southeast High School in 2015 and was majoring in graphic design. He registered for DS services before his first semester in community college. James shared that he was not prepared for college but that he could never be prepared. However when asked what could have helped him be prepared or more prepared, James stated, "I don't think anyone will ever be prepared for when you first go to college." James received accommodations in his English class. He struggled with writing. He was permitted more time on tests, use of a Smart pen, and doing tests in the DS office.

Jessica, a female student of Filipino descent at Western College graduated from Southeast High School in 2015 and was majoring in child development. Jessica felt a bit prepared for college because she was entering college the same time as her sister who also graduated high school in 2015. However, Jessica shared that she has the most difficulty with financial aid, textbooks, and supplies for school. She registered for DS services during the summer prior to the start of school. Her accommodations include math tutoring and a separate location to take her placement tests. When asked what course accommodations she received, Jessica reported that she did not have accommodations.

\section{Pacific Community College}

Fred, a Caucasian male student who attended Pacific Community College graduated from an urban charter school in 2014. He was attending his fourth semester at 
Pacific Community College when he participated in the study. Fred received a lot of support during high school because he and his family worked with Safe Voices, a student community network from Parent Education Network. This program supports students with disabilities, parents, and family members. Fred registered for DS services prior to his first semester. His accommodations include a note taker, taking tests in a separate room, and access to Ultranet media software. Fred was majoring in elementary education and history. He shared that his most difficult challenge was the social aspect of college. In high school, everyone is social but in community college, everyone is independent and it was difficult to make friends.

"I guess I kind of always thought that college was like in the movies. You go to college, you get into a dorm room, you know what I mean, and you make friends-you meet people right away. And you make friends right away. I know that Pacific Community College was a community college, so I knew that there won't be dorms or anything like that. I wouldn't be living on campus but I didn't know that it'll be hard to meet people and I would be lonely because that was definitely the hardest things about my first year that made it so hard with that." (Interview: 3/17/2016) Mary, a female student of Latin descent, graduated from a private high school in 2013 and was in her sixth semester at Pacific Community College. She was pursuing her Associate of Arts in Early Childhood Education and planned to transfer to a four-year 
university. During high school, Mary did not have an IEP and did not have a transition plan. She remembered that she had special education support and services in elementary school because she attended a public school. After she transferred to a private school in fifth grade, all of her special education services ended. When she registered at Pacific Community College, Mary was informed about their DS services during her orientation and decided to make an appointment. She struggled with note taking, preparing for and taking exams, organizing her ideas, writing essays, and processing all of the information presented during class.

Penny, an African American female student at Pacific Community College, graduated high school from Peninsula High School in 2013 and was finishing up her last semester of classes before transferring to a four-year university. She registered for DS services during the summer after high school. Her accommodations included extra time on tests and assignments, a formula card in math, and the use of text-to-speech software. She also received a lot of support from her mother, who also works at Pacific Community College. Penny was majoring in psychology and played basketball for the college. At the time of participation in the study, Penny was getting athletic scholarship offers from multiple universities but had not made a decision yet on where she wanted to attend.

Megan, a Caucasian female student from Pacific Community College graduated from SB High School in 2013 and was majoring in restaurant management and business. She registered for DS services during her first semester in Spring 2014. She was referred 
to the academic counselor because she was failing her courses. Although Megan attended a high school in the same district as Pacific Community College and had an IEP, Megan did not know about the services and support she could receive in college. The academic counselor at Pacific referred her to DS services and Megan began receiving accommodations in her classes. Her accommodations included the use of a Smart pen, a note taker, and speech-to-text software.

\section{High School Preparation}

Nine of the 14 participating community college students with learning disabilities interviewed had reported and believed that their high school had not prepared them for their transition to community college. Priscilla reported that she was ready because she had met with a transition specialist in high school, high school counselor, and college counselor before being admitted to the community college of her choice. Brian felt "50/50" because he had an older sibling who already attended the college. Jasmine described her experience during her transition from a high school to Main Community College as "definitely not prepared - because I am the first generation to go to college, so at first feeling completely alone and not knowing what to do at all. That was a huge challenge. I didn't know anything about financial aid. I didn't know anything about programs. I didn't advocate for myself a whole bunch in the very beginning" (Interview: 3/11/2016). Megan also shared, "I was not really prepared. Because I have learning 
disabilities, I didn't know how to succeed. So it took me a lot longer to complete my general education courses because of my learning disability" (Interview: 2/11/2016).

In addition, this chapter addresses the main research question of what characteristics are essential for students with learning disabilities to successfully transition from high school to college including two sub questions on college readiness and disability awareness: (a) "How do college readiness skills, such as academic behaviors, study skills, and personal attitudes contribute to successful college transition?" and (b) "How does the students' awareness of their disability and their ability to selfadvocate to communicate their disability needs affect their first semester in college?"

The collective story of these students with learning disabilities experiencing the transition from high school to community college was identified through an analysis of both quantitative and qualitative data obtained through surveys and interviews. Revealing a collective story as well as identified individual variations in their preparedness to transition from high school to community college. It also makes known the challenges each student faced, how each student persevered, and the characteristics and/or skills helped them with the transition from high school to college.

The research methodology used was a convergent parallel mixed methods design using both quantitative and qualitative data. An analysis of the data determined that college readiness skills (including organization and time management skills) were among the most important skills to have during the transition from high school to college. 
Intrinsic motivation especially the need to test and challenge oneself (competence) was another important characteristic that students with learning disabilities described as important to the transition process. Self-awareness of their disability and the obtaining and use of accommodations in the classroom and test-taking were identified by this group of students as extremely helpful during the transition process from high school to community college. Lastly, participants felt that relationships and relatedness was very important in high school and in college. These findings contributed to how students transitioned and how they perceived their preparedness for college.

\section{College Readiness Skills}

All of the participants who participated in the study reported that study skills including time management and organization were the most important college readiness skills. It was such an important skill that the students spoke with certainty when talking about how critical it was to have good study skills. As a student who is attempting community college after having dropped out during her first semester, Anna put it this way, "Don't waste your time. Just be very organized, keeping up with the class and doing the homework" (Interview: 3/3/2016). In a similar manner, Jasmine asserted, "Definitely time management. That's a huge thing that I believe in" (Interview: $3 / 11 / 2016)$.

According to Penny who attends a different college, organization and time management, as well as having a positive attitude and persistence, are important for 
success in community college, "I think being organized and time management. Behavior-wise, I think you just need to, well I think attitude, just stay positive. I guess and just keep trying" (Interview: 2/11/2016). Megan also stressed the importance of behavior, in particular, staying on task and not procrastinating. She reported, "One reason is that you need to be able to like stay on task and not procrastinate in college. Because when you procrastinate, then you're not gonna do well in college and you need a lot of time management" (Interview: 2/11/2016).

Mary, who attended a private school prior to community college, reported the importance the importance of managing time wisely and connected time management with stress reduction. In Mary's words, "I would say like one of the most important characteristics a college student is to have in his or her life is time management skills, because in order to be able to have those type of skills, you need to be able to know how to manage your time wisely, and it can also help reduce your stress level, and it can help you also prioritize what needs to get done on each day, and sets you apart from other responsibilities that you need to take care of later on throughout the week" (Interview: 2/11/2016).

Students with learning disabilities reported college readiness skills and attitudes as being very important during the transition from high school to college. However other behavioral characteristics that encompass self-determination were also identified as being 
important. As a general psychological theory of human motivation, three features that foster intrinsic motivation are autonomy, competence, and relatedness.

\section{Intrinsic Motivation}

Of the characteristics ascribed to intrinsic motivation, behaviors associated with competence, which is the need to test and challenge one's abilities (Guiffrida et al. 2013), were the most reported characteristic. Competence is the innate need to feel effective and competent while managing one's own environment (Deci et al., 1991). This includes pushing oneself to the limit, trying one's best, always believing, having confidence and persistence, and never giving up. Of the students that were interviewed, $58.8 \%$ reported that characteristics of competence were an important characteristic.

Brian and Jasmine pushed themselves and never gave up. Brian reported that pushing himself to the limit was important, and it is different than his study behavior in high school. He reported in his interview, "You need to push your limits. And do homework every night. It won't be easy like high school" (Interview: 2/5/2016). Jasmine reported that, "Definitely just always have the thought of you can do it no matter what. Even if you have to try and try again and to never ever give up and being positive through the whole thing is extraordinarily important. Even if you fail, that should only tell you, you know what, I just need to work harder" (Interview: 3/11/2016). Believing that she can do it and trying hard is what motivated Jasmine to keep working hard in college. 
Mary continued to stay positive, encouraged, and motivated during her journey in college. She shared in her interview that a good understanding of self is a useful characteristic to possess. Stating in response to the most essential characteristics needed to be successful in college, "I would say confidence and like positive self-esteem and having motivation and encouragement, because it will not only help you to feel better about yourself, but it will help other people to get a better understanding of who you are" (Interview: 2/11/2016).

Autonomy is developed when students choose to become engaged in learning because the subject and activities are closely aligned with their interest and values (Guiffrida et al., 2013). Nonetheless, only $23.5 \%$ of the students that were interviewed reported that autonomy was important. These students reported motivation, encouragement, being yourself, and knowing what you want to do in life were important characteristics in college. This is how Fred communicated the significance of knowing one's interest and goals, staying persistent, and knowing one's limitations, "I think it's important to know what you want to do in your life. I think it's important to be confident in yourself that you can get it done no matter how long it takes you. You know that you will get it and you'll finish. Know what your limitations are" (Interview: 3/17/2016).

Although Anna did not report about engagement in her interests, she possessed a "mentally tough" attitude with "no excuses" and identified the importance of goal setting and maintaining a positive attitude. Anna stated this belief in the following manner, 
"Probably mentally tough, no excuses mentally. Goal driven. Oh, always a positive attitude if you can, and skills; whatever you need to work on, just work on it a little more every day" (Interview: 3/3/2016).

During the time of data collection for this study, students were mostly working on general education courses and classes that were related to the transition to college coursework, study skills, and their disability. The courses offered at this time were less likely to be geared to their career interests and academic goals.

Another key characteristic often associated with self-determination is relatedness, the need to establish close, secure relationships with others. It was reported as an important characteristic by $17.6 \%$ of the respondents, nonetheless, relationship surfaced as being important when it came to an awareness of their disability, communication with professors, and their transition to college. This included being involved on campus, meeting with counselors, and being social and participating in study groups and being social. As Jasmine stated, "Being involved on campus is extraordinarily important, extremely important. I can't emphasize that enough" (Interview: 3/11/2016). She participated in clubs and organizations, programs for first generation students, and also worked on campus at her community college.

Judy also reported that, "You need to be very outgoing. Yeah, not be shy, and talk and ask for help" (Interview: 2/9/2016). Judy shared about her experiences in high school and how she was shy and quiet. Teachers always made an effort to approach her, 
and she never needed to initiate asking for help. In college, Judy needed to advocate for herself and ask for help when she needed it.

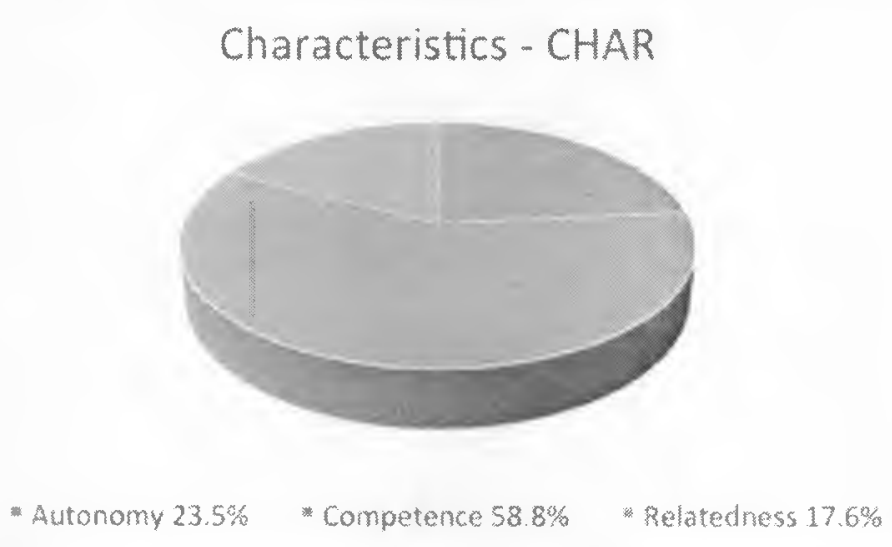

\section{Disability Awareness}

Of the 14 students, 11 students registered and accessed disability programming and services at their school prior to starting school. Most of the students made appointments, brought in previous special education paperwork, and received accommodations at the beginning of their college career. The types of accommodations reported by the students included:

$\begin{array}{ll}\begin{array}{ll}\text { test in a separate location } \\ \text { extra time on tests }\end{array} & \begin{array}{l}\text { access to media software for research } \\ \text { scribe software (speech to text) } \\ \text { audio version of text }\end{array} \\ \begin{array}{l}\text { priority scheduling } \\ \text { note-taker }\end{array} & \text { math tutors } \\ \text { use of a smart pen } & \text { math formula cards } \\ \text { educational planning } & \end{array}$


Candace and Megan waited until they started failing in their classes before registering with disability programming and services. They had not registered earlier due to a lack of knowledge and inadequate guidance from their high school counselor and college academic guidance counselor. Candace's English teacher referred her to DS after the first few assignments, while Megan's counselor referred her to DS because she was failing in all of her classes.

Anna attempted to register for disability services and programming prior to the start of college, but she was unable to. The office was closed when she was there due to campus construction and she was unsuccessful in making an appointment when she called the office. Because of that, she was failing in all of her courses the first semester and she ended up dropping out. At the time of her interview, she had been out of school for over a year and wanted to try again. She reported that the lack of accommodations impacted her greatly, because she would be farther ahead in school if she did not drop out. Anna reported:

"Yes it impacted me I guess a lot. I mean, I didn't end up going back, so probably it wasn't a good thing for me. If I did get accommodations, I may have been guided better, because I had to do everything by myself and I don't really know how to do it..." 
"When I went to DPS my first time, I tried to, but they were still under construction, and the disability number person just wouldn't answer the phone. I was just stuck. The people didn't guide me right, and I would go to the room where they tell me to go, but there's nobody in there and I would call again and just didn't... They would answer and then like they'd put me on hold, tried to transfer me, and the transfer wouldn't go. It just was a big difficult thing so I just dropped it." (Interview: 3/3/2016) Having accommodations during the transition to college was important to a successful college career for students with learning disabilities. Nine students reported that accommodations made a substantial impact because their disability "slows them down," delineated "unnecessary struggle," and made a difference in their life.

When asked how accommodations have impacted his time in college, Fred responded, "Pretty positive and lot of positive ways, especially with the note taker. I know with my auditory deficit, since I don't process well auditorily, having a note taker is very helpful, because if I would try to take notes then I wouldn't be able to process any of the lectures, so having that and going back to the getting my notes then annotating the way I need helps me a lot. I can comprehend better" (Interview: 3/17/2016). 


\section{Self-Advocacy and Communication}

Although self-advocacy was initially thought to be an important characteristic, only one student reported that "asking for help" was an important skill to have. In fact, Priscilla reported that it was a challenge for her, even though she emphasized the need for relationships with counselors and professors. She reported in her interview, "Like I had to go outside of my comfort zone because I'm really comfortable with the people from high school than the people at the community college. And they just really got me connected with people that would help me. My challenges were really just like speaking my mind and standing up for myself and things that I wanted to do and things that I wanted to achieve in my lifetime" (Interview: 2/5/2016).

Students with learning disabilities reported that relationships and relatedness were considered more important to the transition to college. They reported that meeting with counselors at the beginning of their college career, accessing resources and programs, being involved on campus, and building relationships was more important. Selfadvocacy is embedded in these relationships. The more students were involved in college programs, building relationships with faculty and the student community, and being a part of academic resources, the more that these students were learning about the college, asking questions, and advocating without the direct action of self-advocating.

After students access the disability resources, the program office often provides a written communication to the students' professors. These were referred to as a summary 
of accommodations, accommodation letters, and accommodation plans. The students reported that they handed these documents to the professor at the beginning of the course. Sometimes students reported that the disability office would email the professor directly with the list of accommodations. Priscilla, Jasmine, and Megan reported that they provided additional communication to the professors about their disability or accommodations.

\section{Quantitative Findings}

The ARC Self-determination Scale consists of four subscales: (a) behavioral autonomy, (b) self-regulated behavior, (c) psychological empowerment, and (d) selfrealization. Behavioral autonomy is when a person behaves autonomously, independently, and free from any external influence or interference (Wehmeyer, 1995). The behavior is according to the person's own preferences, interests, and abilities. The behavioral autonomy subscale includes 78 items that are divided into self and family care, management, recreational activity, as well as social and vocational activity. Within self and family care, there are item questions that measure basic daily living activities, personal care, and family oriented activities. Within management, there are item questions that measure the degree to which adolescents independently handle their interactions like available resources and personal responsibility for commitments and obligations. Within recreational activity, there are 16 items that evaluate recreational and 
leisure time. Lastly social and vocational activity measures social involvement and vocational goals, plans, and activities.

\section{Behavior Autonomy}

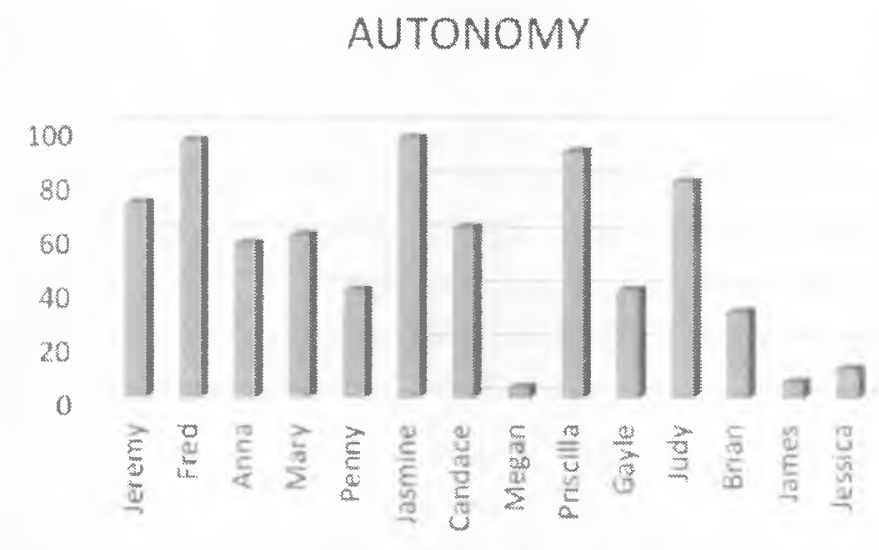

Responses from the participants indicated varying levels of autonomy. On the higher end, Fred, Jasmine, and Priscilla measured the highest percentage of autonomy. Based on their responses, they did their own laundry and went shopping on their own. They had jobs while in school and they had long-term career plans. Conversely, Megan, James, and Jessica's responses resulted in low levels of autonomy. Their responses indicated that they are dependent on their family to care for laundry and make meals, and also, these participants did not have jobs. Although during their interview they shared that they decided on a major, on the ARC Scale, they did not respond that they always make their own long term career plans. 


\section{Self-Regulation}

Self-regulated behavior includes a combination of behavioral and cognitive strategies to achieve behaviors of self-management (e.g., self-monitoring, selfinstruction, self-evaluation, self-reinforcement), goal setting and attainment behaviors, problem-solving behaviors, and observational learning strategies (Wehmeyer, 1995). The self-regulation subscale of the ARC Scale measures interpersonal cognitive problem solving in addition to goal setting and task performance.

\section{Self-Regulation}

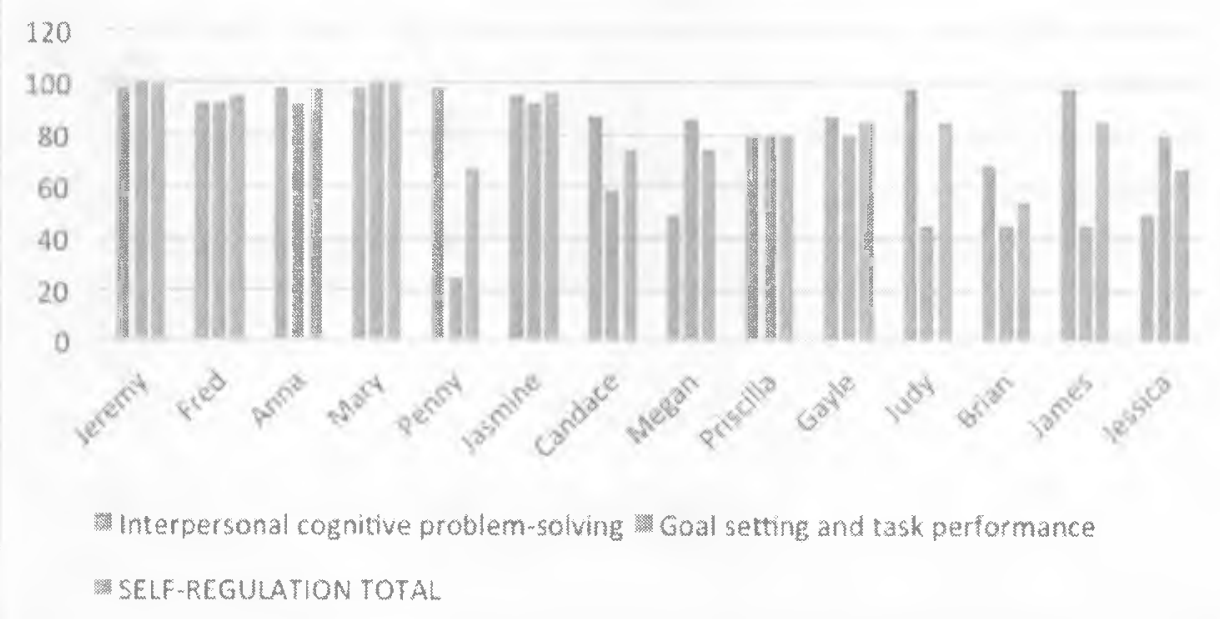

This subscale measures the two areas, interpersonal cognitive problem-solving, in addition to, goal setting and task performance, and then determines a total self-regulation score. On most of these participants, the interpersonal cognitive problem-solving and goal setting/task performance was similar. However, for Penny, Judy, and James, their two subscale scores varied by 53 to 74 points, making their total self-regulation score 
low. Penny's responses for the interpersonal cognitive problems solving led to a high score of 98. In the goal setting and task performance section, she responded with the check box "I have not planned for that yet" rather than providing an explanation on all three of the questions. This led to a raw score of zero and very low standard score of 24 . Judy and James gave one to two responses and also checked the same box "I have not planned for that yet," which also led them to low scores.

Megan and Jessica also had a moderate variance of 30-37 points, but their goal setting/task performance score was higher than their interpersonal cognitive problemsolving scores. The participants were given a beginning and ending to a scenario, and they had to develop a problem solving strategy that would lead to the ending. Megan and Jessica responded to the task but their responses did not lead to problem solving strategies. For example, when presented with "You hear a friend talking about a new job opening at the local bookstore. You love books and want a job. You decide you would like to work at the book store" and the story ends with you working at the bookstore, Megan and Jessica responded with the following:

"I personally hate books buts it is money so it is a 50/50 decision to make." Megan

"You'll have to kindly ask a friend if you can work there a helping hand. If it's your first time to work at a store your friend made, you'll have to apply. Plus, you'll have job experience." - Jessica 


\section{Psychological Empowerment}

Psychological empowerment is the multiple dimensions of control, including cognitive (personal efficacy), personality (locus of control), and motivation (Zimmerman, 1990). The ARC Scale provides a subscale measure of psychological empowerment and measures the respondent's perception of their locus of control, self-efficacy, and outcome expectancy.

Megan and Jessica's levels of psychological empowerment were measured low. Their responses indicated that other people made decisions for them and that they were not likely to share their opinions, might need encouragement to motivate them, and were generally more shy and reserved. On the other hand, Anna, Jasmine, and Judy's responses yielded the maximum score. They perceive themselves as very much in control of their lives, believe in themselves, and expect to achieve.

\section{PSYCHOLOGICAL EMPOWERMENT}

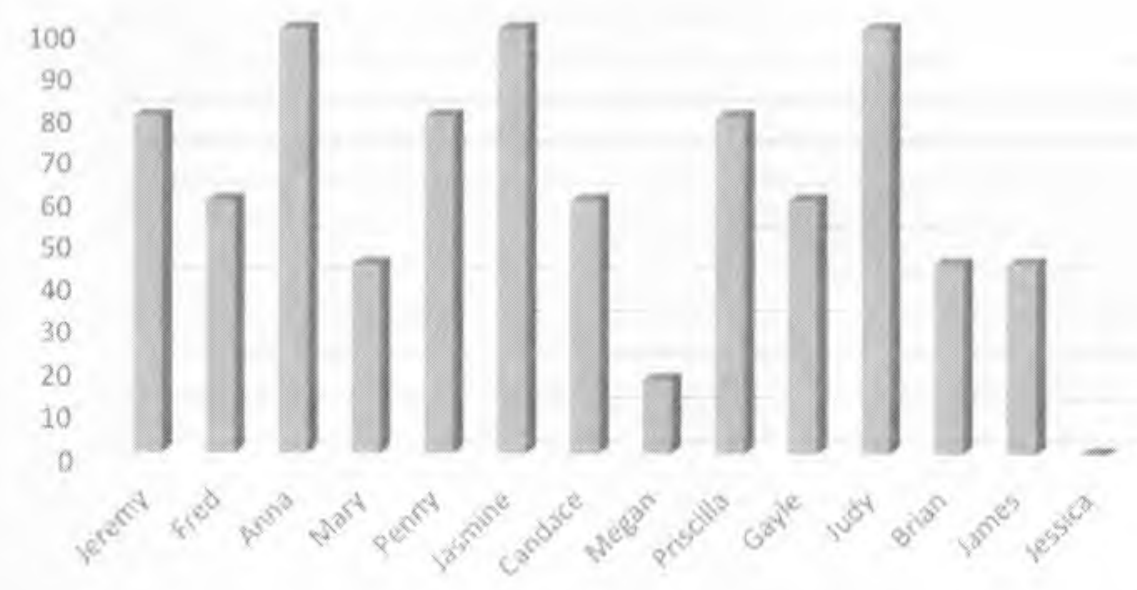




\section{Self-Realization}

Self-realization is knowledge individuals have about themselves including their strengths and limitations to make the most of this knowledge. Self-knowledge, selfunderstanding, and the interpretation of one's environment may influence one's behavior (Wehmeyer, 1995). The self-realization subscale of the ARC Scale includes items that provide information on self-awareness, self-acceptance, self-confidence, self-esteem, and self-actualization.

Nine of the 14 participants perceived themselves as being self-aware, selfconfident, having a good self-esteem, and accepting of themselves as they are. They report that they know their feelings, limitations, and that they are liked. Penny, Megan, Gayle, Brian, and Jessica perceived themselves as not feeling comfortable with their emotions, and they tend to hide their feelings. They all reported that they like themselves and feel that other people like them, but they also reported that they cannot do many things and are afraid of making mistakes. 


\section{SELF-REALIZATION}

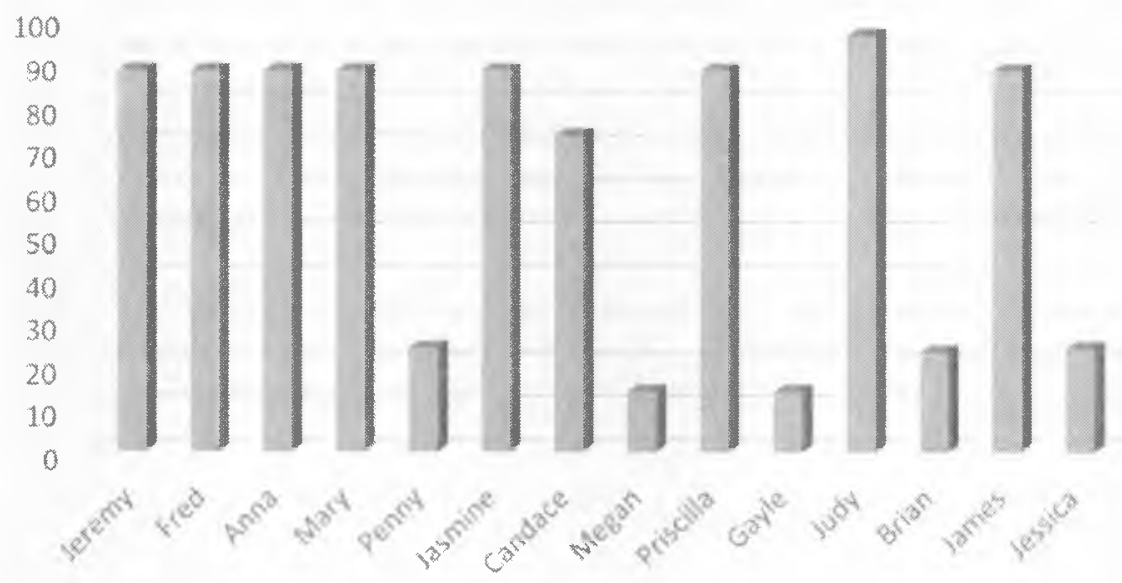

\section{Self-Determination, A Predictor of Academic Success}

This study examined self-determination as measured by the ARC SelfDetermination Scale to be a predictor of academic success. However, the table below presents a low correlation between the overall self-determination total as calculated by the ARC Scale and the participant's GPA during their first semester in college. 


\section{SELF-DETERMINATION \& GRADE POINT AVERAGE}

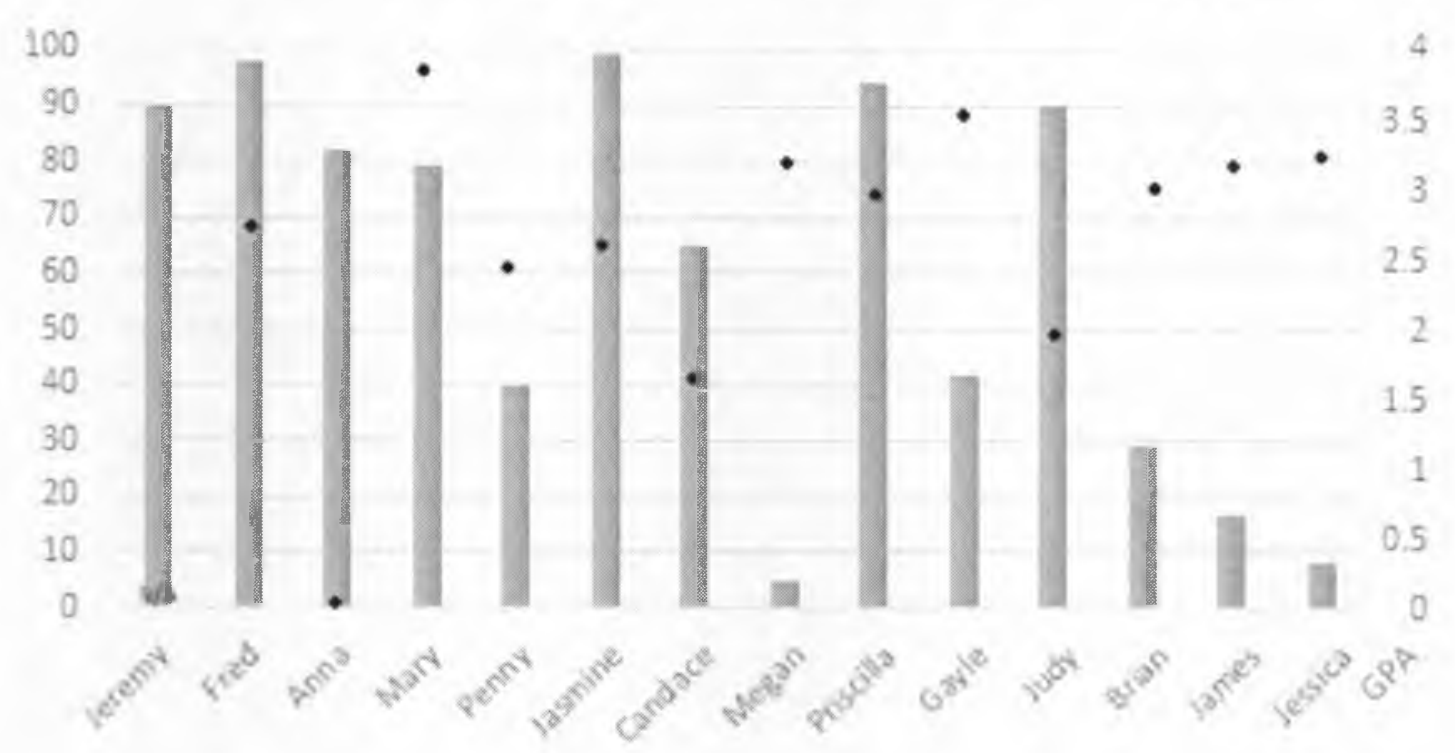

TABLE: Bars represent Total Self-Determination score. Black dots represent Grade Point Average

This table shows that Megan, Gayle, Brian, James, and Jessica measured low on the self-determination scale, while their GPA performance was 3.00 or above. Students with a high self-determination total, such as Jeremy and Anna, did not have a GPA because they either dropped out mid-semester or they did not attend. Judy also scored high on the self-determination scale but only earned a 2.00 during the first semester. She registered for disability services prior to starting her first semester and attended all of her classes. The causes for this discrepancy are dependent on the classes that each student registered for and if the DS program office provided the classes. Many students with learning disabilities register for fundamental courses for writing, math, and lab that are offered by the DS program office. These classes are modified courses that have 
accommodations embedded in them. Other students take the regular college level courses. In these courses, students with learning disabilities tend to struggle and continue to work harder even with their accommodations. During the first semester, Judy took a combination of regular college courses, fundamental courses in writing, and an assistive computer lab provided by the DS program office.

In the case of Anna, the survey resulted in high levels of self-determination in all areas measured. Anna attempted her first semester at a community college and received no accommodations. She did poorly, which led to her leaving school for over a year. During that time, the student was hired in a financial planning company and worked her way up to providing financial advice and planning. The student was in the process of managing her own branch office with a staff of three other people. The results of her self-determination scale reflected on her self-determination toward life rather than a measure of her self-determination as she transitioned from high school to community college

\section{Triangulation of Findings}

After analyzing quantitative and qualitative data individually, the evaluation methods were attempted to triangulate the data that was used. Most of the data results were consistent between the interview responses and the scores generated by the ARC Self-Determination Scale. When comparing characteristics of intrinsic motivation, as reported in the interview, the same students with learning disabilities who provided more 
responses that promoted autonomy and competence, were the same students who scored high on the scales of behavioral autonomy, psychological empowerment, and in selfrealization.

However, the scores from the subscale of self-regulation were not conclusive. Because this subscale measures both interpersonal cognitive problem solving and goal/setting task performance, the responses may be varied and discrepant. Participants might report that they have good problem-solving abilities, but their answers to the goal/setting task performance might have resulted in a low score. This particular section is based on both areas of measure. For example, if a participant already has a car and answers the question about planning for transportation, then they may choose "not planned" because they already have a car. Because the participant chooses "not planned," this will result in a score of " 0. ."

When comparing the results of the qualitative data, one of the areas that is not measured by ARC Scale and was lacking in the quantitative data is the need for relatedness or how important building relationships are in self-determination. Responses from the interviews indicated that relatedness and relationships were important in disability awareness, as well as in advocating and communicating their needs. This area needs to be added to the ARC Scale if measuring self-determination and intrinsic motivation. 
Autonomy as measured in the ARC was not addressing self-determination in the community college transition. Most areas that were explored were in self and family care, the management of interaction with the environment, recreational activity, and social and vocational activity. There were a couple of questions of the 32 that asked the participant "I work on school work that will improve my career chances" and "I am involved in school-related activities" that seemed related to the transition from high school to community college. Other questions include "I make my own meals or snacks" and "I listen to music that I like."

\section{Summary of Findings}

The results of this study concluded that college readiness skills, such as academic behaviors and study skills were very important characteristics that contribute a successful college transition. In particular, time management and organization were reported as the most important skills that students with learning disabilities needed to be successful during their transition to college.

Personal attitudes and beliefs were also reported as being important during the transition from high school to college. Competence, one of the characteristics of intrinsic motivation was a significant trait as $58.8 \%$ of the students that were interviewed reported this innate need to feel effective and competent. They reported pushing themselves to the limit, trying their best, always believing, having confidence and persistence, and never 
giving up. These students also reported as having higher levels of psychological empowerment as measured by the ARC Self-Determination Scale.

In addition, the results of this study also addressed how aware students with learning disabilities are about their disability and if they are able to self-advocate by communicating their disability needs effectively. As the students reported their disability awareness, all of the students discussed how they acquired accommodations and how accommodations helped them. Many of the students made appointments with the DS programs prior to starting their first semester; however, there were a few students that did not get referred until they started failing in their courses.

Although none of the students reported "self-advocacy" as a characteristic, a few of them mentioned how "asking for help" was an important skill to have. Many students also reported that building relationships with DS staff, college counselors, and professors was important to a successful transition to college. They felt more comfortable asking for assistance or guidance from people that they knew.

All of these characteristics were essential for students with learning disabilities to successfully transition from high school to college. Although more than half of the students did not feel prepared when they transitioned, they identified skills, attitudes, and beliefs that helped them while they attended community college. Of the characteristics that they reported, organization and time management were the only two that were behaviors and not directly related to self-determination. Motivation, especially the 
characteristics of intrinsic motivation, competence, autonomy, and relatedness, as well as psychological empowerment, self-regulation, and self-realization, were important characteristics reported by the participants with learning disabilities who transitioned from high school special education programs to community college disability programs. 


\section{Chapter 5: Discussion and Recommendations}

The purpose of this mixed methods research study was to learn more about how students with learning disabilities navigate through the community college system during their first year as a college student. This study concluded that $64 \%$ of students with learning disabilities did not feel that their high school had prepared them for their transition to community college. Some of the characteristics that were identified in the findings of this study are college readiness skills (including organization and time management), which are some of the most important skills to have during the transition from high school to college. Intrinsic motivation, especially the need to test and challenge oneself (competence), was also reported as behaviors and attitudes that students with learning disabilities needed during the transition from high school to college. The importance of relationships and relatedness was very important in high school and in college as reported by the participants. These relationships, in addition to an awareness of their disability, helped with receiving appropriate accommodations in the classroom to help students with learning disabilities access the academic material and be successful in their coursework.

\section{High School Preparation}

More than half of the participants reported that they did not feel that their high school prepared them for their transition to community college. All of the students had 
transition plans as part of their IEP in special education, but transition support and guidance varied among different high schools, as well as between students that attended the same high school. These inconsistencies led to many students feeling unprepared, unconfident, and lacking self-determination during the high school to community college transition. However, a few other students with learning disabilities felt confident, empowered, and ready for college when they graduated high school. They knew what their resources were, how to navigate through the system, and if they did not have the knowledge, they knew how to get their needs met.

California needs to consider standardizing transition programming and curriculum for students with learning disabilities. At this time, much of the curriculum is focused on career planning and independent living. The curriculum needs to start when students first enter high school and should include college planning as well as vocational and career planning. As students near graduation, high school transition programs need to bridge the gap between high school special education and disability service programs at local community colleges. This may include transition to college courses that students may take at a neighboring college that will teacher students how to navigate through the college campus and resources.

Financial aid should also be included in this transition and college preparation curriculum as a few students in the study felt the financial burden when they transitioned to community college. Jessica shared, "I was a bit prepared, but I think money is a 
challenge because of financial aid. And plus books are expensive to buy" (Interview: 2/10/2016). When asked what kind of advice she would give her former high school teachers, Jasmine, who is a first generation college student, reported, "I wish they talked to us more about probably financial aids on campus... And maybe just scholarship a little more and I guess just different resources. I wished they told me about other resources they have on campus" (Interview: 3/11/2016).

\section{College Readiness Skills}

Organization and time management skills were consistently reported as some of the most important skills for students to have during the transition from high school to college. These skills are reported as being difficult to develop by students with learning disabilities, as determined by a self-regulation study in 2003 by Ruban et al. Students with learning difficulties lacked academic self-regulation and were reported to work harder to develop an effective reading system, take good notes, organize their study time, manage their academic assignments, and approach test-taking situations effectively (Ruban et al., 2003). However, when analyzing the quantitative data provided by the participants who completed the ARC Scale, the results had some inconsistent totals. Because some of the students answered with "I have not planned for that yet" rather than providing an explanation on goal setting, their self-regulation total scores were low. The ARC Scale was not measuring goal setting as accurately as intended. 
Although organization and time management skills are important during college and in life for everyone with or without a disability, this sample population of students with learning disabilities consistently reported them as being the most important. Because of the difficulties that these students have on developing good academic study skills, it is important to address these skills in high school for college readiness.

Special education staff members are serving and supporting students with learning disabilities during high school. These staff members often help with organization, keeping the assignments current, and managing the workload. They provide extra study time and space in addition to extra guidance on assignments. Although these supports are provided as part of their IEP, these accommodations may also be hindering the student if they are not learning how to organize and manage their time and workload, but are allowing adults to do it. Ryan shared about the difference between high school and college courses, "Yes it's similar to high school but more advanced. More advanced teaching and more responsible. And teachers won't tell you to do your homework or turn in your homework on that due date. And that's more responsibility" (Interview: 2/5/2016).

\section{Intrinsic Motivation}

Competence, the need to test and challenge oneself, was reported as important behaviors and attitudes that students with learning disabilities need to have during the transition from high school to college. Of the three characteristics of intrinsic motivation, 
competence is the innate need to feel effective and competent while managing one's own environment (Deci et al., 1991).

The other two characteristics of intrinsic motivation are autonomy and relatedness. Autonomy is developed when students choose to become engaged in learning behavior and the subject and activities are closely aligned with their interests and values (Guiffrida et al., 2013). The qualitative interviews suggested that this included being motivated, encouraged, being yourself, and knowing what you want. Priscilla stressed the important of keeping a positive attitude, as well as knowing one's game plan, in her interview. "Knowing your game plan before you go to college. Or know what you want to do before you get there... You have to have a positive attitude. A positive attitude when you get to college. If you don't have a positive attitude, it will carry with you through the whole semester" (Interview: 2/5/2016).

Jeremy was in his first semester at Main Community College, but he stressed the importance of "Just be you and do you." When asked what advice he wished he had before starting community college, Jeremy responded, "Just tell me to do me and be happy. Because once you're in college, no one really cares what you do or what you look like or whatever" (Interview: 2/12/2016).

Lastly, relatedness is the need to establish close and secure relationships with others. Of the respondents, $17.6 \%$ reported that it was an important characteristic during the transition from high school to college. Although relatedness was not reported the 
most important characteristic within areas of intrinsic motivation, relationships and communication were reported as important when acquiring support and services to help students with learning disabilities be successful in their courses.

\section{Relationships, Relatedness, and Awareness}

The importance of relationships and relatedness were reported as being very important when asked about accommodations that students with learning disabilities received in their courses because of their disability. Students were also more confident and comfortable about acquiring accommodations when they had more awareness of their disability strengths and weaknesses. Mary reported, "I would say approaching my professors and letting them know about my accommodations and getting that extra support in my academics would say it has really changed my life and not only academically but emotionally as well" (Interview: 2/11/2016).

Awareness of strengths and weaknesses and the ability to express this awareness to college counselors and professors, awareness of services and accommodations, and the ability to request these accommodations when appropriate help students with learning disabilities advocate for themselves in college (Schutz, 2003). Jasmine shared in her interview, "I do let instructors know (about accommodations) just because I bug the on their office hours a lot and I want them to know that I will be bugging them on their office hours" (Interview: 3/11/2016). 
When building relationships with disability services staff, college counselors, and course professors, students are a lot more comfortable discussing their disability, services, and accommodations, and they ask for help. Priscilla was one of the participants who felt prepared during her transition from high school to college. "I was prepared pretty good because I was meeting with people from K5 (transition office in high school), people like my high school counselors, and I went over and beyond meeting with some of the counselors at South Bay Community College" (Interview: 2/5/2016).

However, it is also important for students with learning disabilities to be comfortable with their disability. Penny gave advice to other students with learning disabilities and said, "The first thing I would tell them is to accept it and realize that there's nothing wrong with it. There's actually a lot of people with learning disabilities and then after accepting it, look for help with that disability or any programs to help you with that disability. Because a lot of people come to college and they just like this is hard and they kind of just go through the flow of classes and they end up failing or messing up and they don't realize that there's a lot of programs out there that could help you with what you're struggling with" (Interview: 2/11/2016).

\section{Limitations of the Study}

This study warranted some limitations worth noting, which should be viewed with caution when reviewing the findings. The quantitative portion of this mixed-methods study broadened the general scope of self-determination. This particular study was aimed 
to focus on high school transition, preparation of college, and the characteristics needed to be successful in college; however, collecting data using the ARC Scale measured general overall self-determination in all aspects of a student's life, such as family, work, independent living skills, and personal goals.

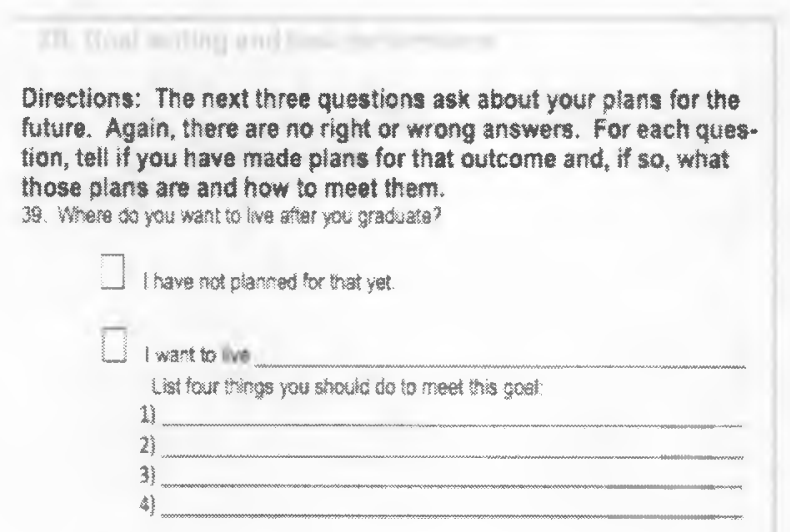

30. Mhers do you wats to work ather you grativate?

D. Mave not mannec tor hat yet.

I wart to wox

List ouk thros you should oc to nest th s gat:

i)

2)

3).

4).

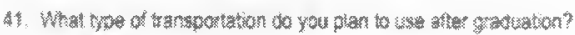

- I have not planned for that yet.

toman to sise

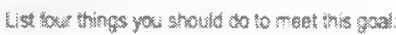

1)

2)

3).

4).
Also within the ARC Self-

Determination Scale, the measure of selfregulation included a goal setting and task performance subscale. This scale asked three questions: (a) "Where do you want to live after you graduate?" (b) "Where do you want to work after you graduate?" and (c) "What type of transportation do you plan to use after graduation?" The participants had two options. They could choose "I have not planned for that yet," which ultimately led to no points, or they could answer with a goal and list up to four things that they had to do to meet the goal. If they listed four things, they

would receive four points, and if they listed one thing, they would only receive one point. 
Some of the participants of the study checked off that they "have not planned for that" because they were already living outside of the family home and/or had already started working. Some of the participants already had cars, so they did not have to plan for transportation. Because of these factors, their goal setting scores were low and their overall self-regulation scale scores were also low. This particular scale did not accurately measure goal setting, but rather measured how the participant answered the question.

Another limitation of the study was due to grade point average (GPA). When reviewing college transcripts and using GPA as a quantitative measure, it is important to note that GPA is an overall average score, rather than grades specific to academics. A student could take non-academic courses with no accommodations during their first semester, such as physical education courses, get straight As, and their GPA would be a 4.00. Most of the students in the study balanced their schedule with academic courses, as well as courses that were less demanding. Students who are enrolled in DS programs are also encouraged to take courses that focus on study skills or writing essentials. Using student performance and GPAs during the first semester to measure success may not be the most reliable and accurate measure. Also in the first semester, the student can enroll in classes and then withdraw in the middle and their GPA will not be affected.

Generalizability was another limitation, as it was unwarranted that the participants were from one particular regional area. Students recruited from Pacific Community College attended different high schools (e.g., private, comprehensive, charter); however, 
all of the students attended high schools in school districts in Northern California. The students who were recruited from Southeast High School attended different community colleges after high school. They all graduated from Southeast High School and attended special education programming. Many reported different experiences while in special education, but they all participated in the same high school transition program. Using a sample population from high schools and community colleges in Northern California was only a small subset of the population being studied.

\section{Implications for Further Research and Practice}

This study expanded the knowledge base related to assisting educational leaders in addressing transition as an equity issue, as students with learning disabilities have the same education opportunities available to them as students without disabilities. Previous studies have examined self-determination in transition by researching transition planning and involvement, high school transition programs and content, self-determination instruction and learning models, and success and learning outcomes; however, this study was focused on how students with learning disabilities perceived their transition and what supports and services they felt they needed to be successful.

The ARC Self-Determination Scale is an established and well-known instrument in studying self-determination; however, this study only used the composite measures of behavioral autonomy, self-regulation, psychological empowerment, and self-realization. Within the section measuring behavioral autonomy, there were subgroups that were 
examined. Independence included two different subsections. One section was for independence for personal care and family oriented functions, and another section was for independence of interactions within the environment. Another subgroup included acting on the basis of preferences, beliefs, interests, and abilities. This group was divided into four sub-areas: (a) recreation and leisure, (b) community involvement and interaction, (c) post-school directions, and (d) personal expression.

Although the composite of behavioral autonomy provided a breakdown of different areas of concentration, this study used the overall composite score as a measure of autonomy. The data from each composite could be analyzed and expanded into another research study measuring different types of autonomy and how autonomous students with learning disabilities are in different aspects of their life.

Lastly, this study was conducted with the medical or individual model perspective of disability, which views disability as an "impairment." In viewing disability literature, the medical or individual model asserts people are disabled by their impairments or differences. "...Impairments are presented as the root cause of the problem of disability... that must be eradicated, minimized or "cured"" (Barnes 2012, p. 3). The problem of disability is placed on the individual due to their individual impairment and the need for medical interventions so that they are able to adapt to society. Our society and education system imposes disability on top of impairments that significantly contribute to unnecessarily isolation and exclusion from full participation in education, 
resulting in the oppression and marginalization of students with learning disabilities (Anastasiou \& Kauffman, 2013).

In contrast, when viewing disability, the social model focuses on the need to change society to enable people living with disabilities to fully participate in society. There is an appreciation that society and institutions, including educational institutions, can do a great deal to lessen and ultimately break down the barriers that prevent persons with disabilities from having access of opportunity. The social model of disability developed by Oliver (1986) is important to a discussion related to how our educational systems either support or limit the access of students with learning disabilities to the same educational opportunities as nondisabled students.

Although one of the questions in this study addressed how other people's perceptions of disability affected how the participants were treated in college, this area could be expanded into a larger study. Keeping aligned with social justice perspectives, education researchers and educational leaders can change how disability is viewed in education by continuing this research and making systemic changes in education. Additional research would be helpful in this area to expand the field of disability perception and behaviors towards students with learning disabilities. 


\section{References}

Abreu-Ellis, C., Ellis, J., \& Hayes, R. (2009). College preparedness and time of learning disability identification. Journal of Developmental Education, 32(3), 28-38.

Anastasiou, D. \& Kauffman, J.M. (2013). The social model of disability: Dichotomy between impairment and disability. Journal of Medicine and Philosophy, 38, 441459.

Anctil, T. M., Ishikawa, M. E., \& Scott, A. T. (2008). Academic identity development through self-determination. Career Development for Exceptional Individuals, $31(3), 164-174$.

Barnes, C. (2012). Understanding the social model of disability. Routledge Handbook of Disability Studies. Oxon and New York: Routledge.

Carter, E. W., Lane, K.L., Pierson, M.R., \& Glaeser, B. (2006). Self-determination skills and opportunities of transition-age youth with emotional disturbance and learning disabilities. Exceptional Children, 72(3), 333-346.

Carter, E.W., Trainor, A., Owens, L., Sweden, B., \& Sun, Y. (2010). Self-determination prospects of youth with high-incidence disabilities. Journal of Emotional and Behavioral Disorders, $18(2), 67-81$.

Cortiella, C., \& Horowitz, S. H. (2014). The state of learning disabilities: Facts, trends and emerging issues. New York: National Center for Learning Disabilities. 
Creswell, J. W., \& Plano-Clark, V. L. (2011). Designing and conducting mixed methods research. Thousand Oaks, CA: Sage Publications, Inc.

Conley, D. T. (2007). Redefining college readiness. Eugene, OR: Educational Policy Improvement Center.

Connor, D. J. (2012). Actively navigating the transition into college: Narratives of students with learning disabilities. International Journal of Qualitative Studies in Education, 25(8), 1005-1036.

Deci, E. L., Vallerand, R.J., Pelletier, L.G., Ryan, R.M. (1991). Motivation and education: The self-determination perspective. Educational Psychologist, 26(3), $325-346$.

Deci, E. L., \& Chandler, C. L. (2001). The importance of motivation for the future of the LD field. Journal of Learning Disabilities, 19(10), 587-594.

Deci, E. L., \& Ryan, R. M. (1985). Intrinsic motivation and self-determination in human behavior. New York, NY: Plenum.

Denhart, H. (2008). Deconstructing barriers: Perceptions of students labels with learning disabilities in higher education. Journal of Learning Disabilities, 41(6), 483-497.

Field, S., \& Hoffman, A. (2007). Self-determination in secondary transition assessment. Assessment for Effective Intervention, 32(3), 181-190. 
Finn, D., Getzel, E. E., \& McManus, S. (2008). Adapting the self-determined learning model for instruction of college students with disabilities. Career Development for Exceptional Individuals, 31(2), 85-93.

Gabel, S.L. (2006). Applying disability theory in educational policy: NIDRR's "New Paradigm of Disability" as a cautionary tale. Chapter 10 in Vital Questions Facing Disability Studies in Education, New York: Peter Lang Publishing, 180-200.

Garrison-Wade, D. F., \& Lehmann, J. P. (2009). A conceptual framework for understanding students' with disabilities transition to community college. Community College Journal of Research and Practice, 33, 415-443.

Green, J. C., Caracelli, V. J., \& Graham, W. F. (1989). Toward a conceptual framework for mixed-method evaluation design. Educational Evaluation and Policy Analysis, $11(3), 225-274$.

Gregg, N. (2007). Underserved and unprepared: Postsecondary learning disabilities. Learning Disabilities Research \& Practice, 22(4), 219-228.

Grubb, W. N., \& Gabriner, R. (2013). Basic skills education in community colleges. New York, NY: Routledge.

Guiffrida, D.A., Lynch, M.F., Wall, A.F., \& Abel, D.S. (2013). Do reasons for attending college affect academic outcomes? A test of a motivational model from a selfdetermination theory perspective. Journal of College Student Development, 54(2), 121-139. 
Hadley, W. M. (2006). L.D. students' access to higher education: Self-advocacy and support. Journal of Developmental Education, 30(2). 10-16.

IDEA Regulations. (2004). U.S. Department of Education, Office of Special Education Programs'. Retrieved from http://idea.ed.gov.

Jameson, D. R. (2007). Self-determination and success outcomes of two-year college students with disabilities. Journal of College Reading and Learning, 37(2), 26-45.

Janiga, S. J., \& Costenbader, V. (2002). The transition from high school to postsecondary education for students with learning disabilities: A survey of college service coordinators. Journal of Learning Disabilities, 35(5), 462-479.

Kirst, M. W., \& Venezia, A. (2004). From high school to college: Improving opportunities for success in postsecondary education. San Francisco, CA: JosseyBass Publishers.

Kochhar-Bryant, C., Bassett, D. S., \& Webb, K. W. (2009). Transition to postsecondary education for students with disabilities. Thousand Oaks, CA: Corwin Press.

Lombardi, A. R., Murray, C., \& Gerdes, H. (2012). Academic performance of firstgeneration college students with disabilities. Journal of College Student Development, 53(6), 811-826.

Miles, M.B., Huberman, A.M., \& Saldana, J. (2014). Qualitative data analysis: A methods sourcebook. Thousand Oaks, CA: Sage Publication. 
Milsom, A. \& Dietz, L. (2009). Defining college readiness for students with learning disabilities: A Delphi study. Professional School Counseling, 12(4), 315-323.

Milsom, A., \& Hartley M. T. (2005). Assisting students with learning disabilities transitioning to college: What school counselors should know. Professional School Counseling, 8(5), 436-441.

Morningstar, M.E., Frey, B. B., Noonan, P.M., Ng, J., Clavenna-Deane, B., Graves, P., Kellems, R., McCall, Z., Pearson, M., Wade, D.B., \& William-Diehm, K. (2010). A preliminary investigation of the relationship of transition preparation and selfdetermination for students with disabilities in postsecondary educational settings. Career Development for Exceptional Individuals, 33(2), 80-94.

National Council on Disability (2003). People with Disabilities and Postsecondary Education. [Position paper]. Retrieved from http://www.ncd.gov/publications/2003/Sept152003.

Office of Civil Rights (2011). U.S. Department of Education. Retrieved from http://www2.ed.gov/about/offices/list/ocr/index.html.

Oliver, M. (1986). Social policy and disability: Some theoretical issues. Disability, Handicap, \& Society, 1, 5-17.

Patrick, S., \& Wessel R. D. (2013). Faculty mentorship and transition experiences of students with disabilities. Journal of Postsecondary Education and Disability, 26(2), 105-118. 
Ruban, L.M., McCoach, D.B., McGuire, J.M., Reis, S.M. (2003). The differential impact of academic self-regulatory methods on academic achievement among university students with and without learning disabilities. Journal of Learning Disabilities, 26(3), 270-286.

Schutz, P. F. (2002). Transition from secondary to postsecondary education for students with disabilities: An exploration of the phenomenon. Journal of College Reading and Learning, 33(1), 46-61.

Shogren, K. A., \& Plotner, A. J. (2012). Transition planning for students with intellectual disability, Autism, or other disabilities: Data from the National Longitudinal Transition Study-2. Intellectual and Developmental Disabilities, 50(1), 16-30.

Skinner, M. E. (2004). College students with learning disabilities speak out: What it takes to be successful in postsecondary education. Journal of Postsecondary Education and Disability, 17(2), 91-104.

Venezia, A. \& Jaeger, L. (2013). Transitions from high school to college. The Future of Children, 23(1), 117-136.

Wehmeyer, M. L, Palmer, S.B., Soukup, J.H., Garner, N.W., \& Lawrence, M. (2007). Self-determination and student transition planning knowledge and skills: Predicting involvement. Exceptionality, 15(1), 31-44.

Wehmeyer, M. L., Palmer, S.B., Williams-Diehm, K., Shogren, K.A., Davies, D.K., \& Stock, S. (2011). Technology and self-determination in transition planning: The 
impact of technology use in transition planning on student self-determination. Journal of Special Education Technology, 26(1), 13-24.

Wehmeyer, M. L., Shogren, K.A., Palmer, S.B., Williams-Diehm, K.L., Little, T.D., Boulton, A. (2012). The impact of the self-determined learning model of instruction on student self-determination. Exceptional Children, 78(2), 135-153. Wehmeyer, M. L. (1995). The Arc's Self-Determination Scale: Procedural Guidelines. Washington, DC: The Arc of the United States.

Wolman, J. M., Campeau, P.L., Dubois, P.A. (1994). AIR Self-Determination Scale and User Guide. Washington, DC: American Institute for Research.

Zimmerman, M. A. (1990). Toward a theory of learned hopelessness: A structural model analysis of participation and empowerment. Journal of Research in Personality, 24, 71-86. 
Appendices 
Appendix A: Informed Consent

\author{
San Francisco State University \\ Informed Consent to Participate in Research \\ Special Education Transition: Preparing Students with \\ Learning Disabilities for Post-Secondary Education
}

\title{
A. PURPOSE AND BACKGROUND
}

The purpose of this research is to better understand how specific characteristics of students with learning disabilities make for a better transition from high school to community college. It has the potential to expand the knowledge base related to the transition of learning disabled students, in particular the characteristics that seem to best serve students in having a successful first year in college. The researcher, Julie Jang, is a graduate student/professor at San Francisco State University conducting research for an educational doctorate in the Graduate College of Education. You are being asked to participate in this study because you have been identified for a learning disability prior to graduating high school and have been attending community college during fall semester 2015.

\section{B. PROCEDURES}

If you agree to participate in this research, the following will occur:

- You will schedule a time to meet with the researcher at her office at Milpitas High School, at the Disability Resource Center at Skyline College, or at a mutually agreed location.

- You will complete the ARC's Self-Determination Scale by paper survey for 10 minutes.

- You will be interviewed by researcher using semi-structured questions for about approximately 30 minutes about your experience with your transition from high school to college.

- Participants will be offered an opportunity to add additional comments and suggestions.

- Total time commitment will be 40 minutes. 


\section{RISKS}

There is a risk of loss of privacy. However, no names or identities will be used in any published reports of the research. The researcher will be conducting the interview out of the hearing range of others.

\section{CONFIDENTIALITY}

The research data will be kept in a secure location and only the researcher will have access to the data. All research data will be stored in an encrypted document on a password-protected computer. The researcher will be transcribing the data using an alias rather than your real name. After transcription, the audio recording will be destroyed. Only the researcher will have access to the research data and it will be stored on a password-protected computer in a locked cabinet The data will be stored on a password-protected computer in a locked cabinet at SFSU's Burk Hall, Room 246 (advisor Professor Davide Celoria's office, a secure location). The data will be stored for 3 years after the research study has been complete.

\section{DIRECT BENEFITS}

There will be no direct benefits to the participant.

\section{E. COSTS}

There will be no cost to you for participating in this research.

\section{F. COMPENSATION}

There will be no compensation for participating in this research.

\section{G. ALTERNATIVES}

The alternative is not to participate in the research. This is a voluntary study and you are able to stop participating at any time of the research process.

\section{H. QUESTIONS}

You have spoken with Julie Jang about this study and have had your questions answered. If you have any further questions about the study, you may contact the researcher by email at juliej@mail.sfsu.edu or you may contact the researcher's advisor, Professor Davide Celoria at dceloria@sfsu.edu. 
Questions about your rights as a study participant, or comments or complaints about the study, may also be addressed to the Human and Animal Protections at (415)338-1093 or protocol@sfsu.edu.

\section{CONSENT}

You have been given a copy of this consent form to keep.

PARTICIPATION IN THIS RESEARCH IS VOLUNTARY. You are free to decline to participate in this research, or to withdraw your participation at any point, without penalty. Your decision whether or not to participate in this research will have no influence on your present or future status at San Francisco State University.

Signature

Date:

Research Participant

Signature

Date:

Julie Jang, Researcher 


\section{Appendix B: ARC's Self-Determination Scale1}

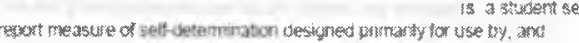

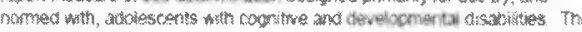
scale ixs nto pirinary auposes

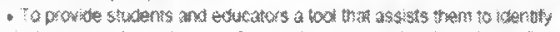

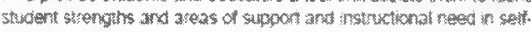
Heternirition and

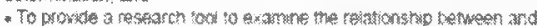

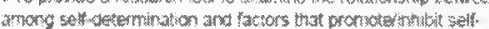

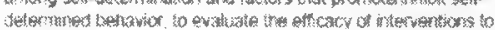

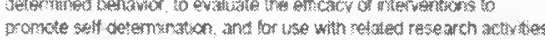

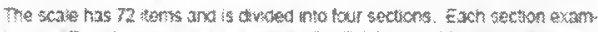
ines a alterent

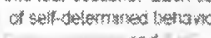

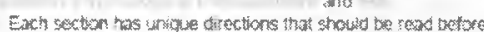

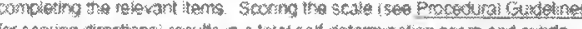

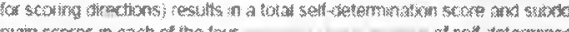

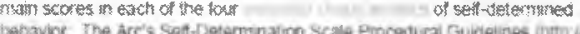

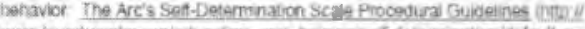

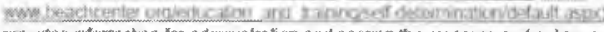

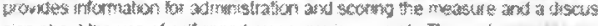

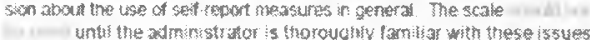

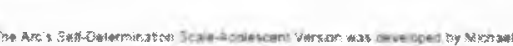

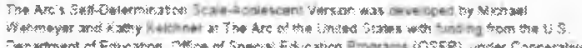

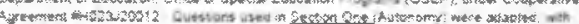

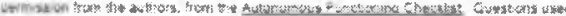

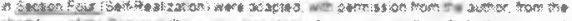

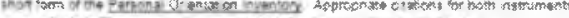

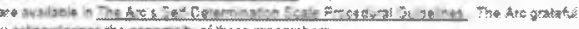

The Arc's

Self-Determination Scale

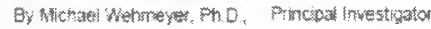

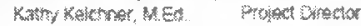
Seff Cotemsnation Assessment Prowect

Student's Name

Date

School

Teacher's name

The Arc

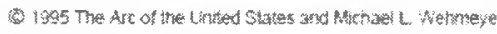




\begin{tabular}{|c|c|c|c|c|}
\hline \multirow[b]{2}{*}{ 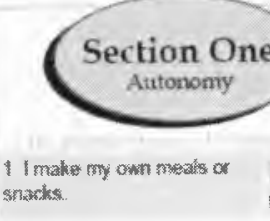 } & \multicolumn{4}{|c|}{ 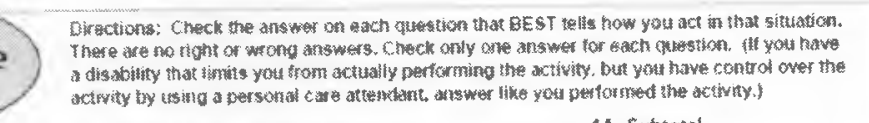 } \\
\hline & 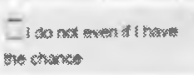 & 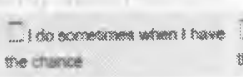 & 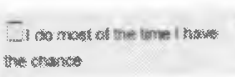 & 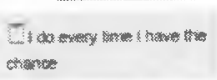 \\
\hline 2.1 care bor my own chathes & El wo nat siven HI have & -i do scriedrea when i have & 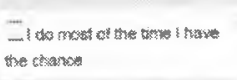 & 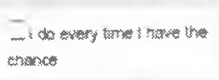 \\
\hline 3. Ito chores in my horre. & 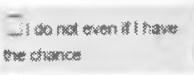 & 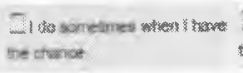 & 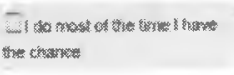 & 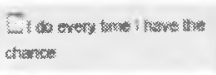 \\
\hline $\begin{array}{l}4 \text { / kepo mow ow persolat } \\
\text { tems tagether }\end{array}$ & 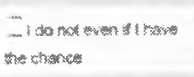 & 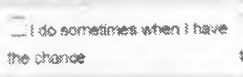 & 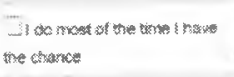 & 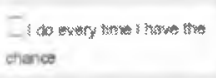 \\
\hline $\begin{array}{l}\text { 5. I do simgle first and or mast- } \\
\text { cal care for myself. }\end{array}$ & 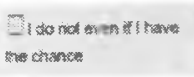 & 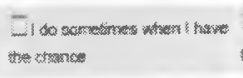 & 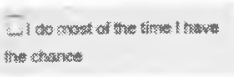 & Il owery the inde \\
\hline $\begin{array}{l}\text { 6il lleses good pessenal care } \\
\text { and grooming. }\end{array}$ & 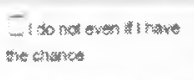 & 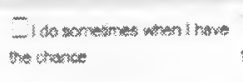 & 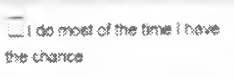 & 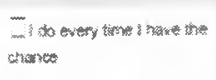 \\
\hline 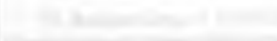 & 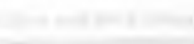 & $w$ & \multicolumn{2}{|c|}{ 18. Subtotal } \\
\hline $\begin{array}{l}7 \text { Intake frends with other } \\
\text { Wids my age. }\end{array}$ & 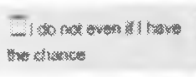 & 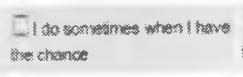 & 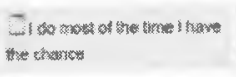 & 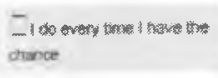 \\
\hline 8 luse the post offica & 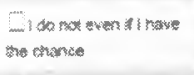 & 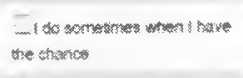 & 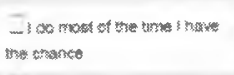 & 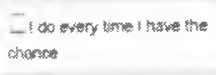 \\
\hline 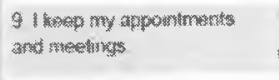 & 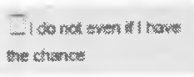 & 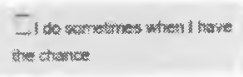 & 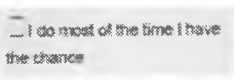 & 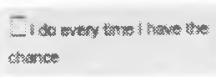 \\
\hline $\begin{array}{l}\text { 10. I texi wath saless people at } \\
\text { stores and tectaurants. }\end{array}$ & 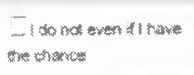 & 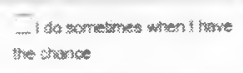 & 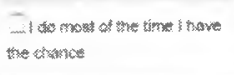 & 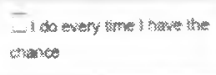 \\
\hline
\end{tabular}

\begin{tabular}{|c|c|c|c|c|}
\hline $\begin{array}{l}\text { 12. I plan wethend activities that I } \\
\text { ane to do }\end{array}$ & $\begin{array}{l}\text { I ido nat avent it i haw } \\
\text { the strance }\end{array}$ & 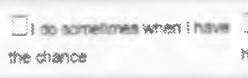 & 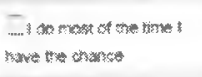 & 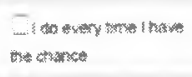 \\
\hline $\begin{array}{l}\text { 13. I am nuched in schood } \\
\text { nolated activitues. }\end{array}$ & 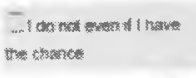 & 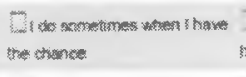 & 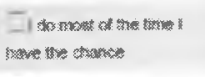 & 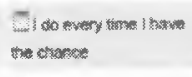 \\
\hline $\begin{array}{l}\text { 14 Wy treethdo and I choose actur } \\
\text { iteses that we kart to do. }\end{array}$ & 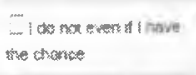 & 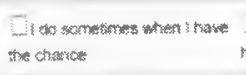 & 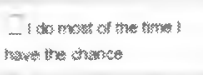 & 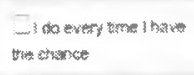 \\
\hline 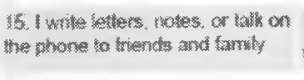 & 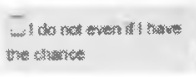 & 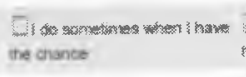 & Fi da mosect of the rises & If enomy tome i fave \\
\hline 16 I listen to musstc that I ike & 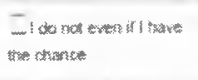 & 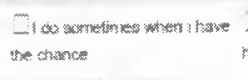 & 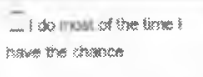 & 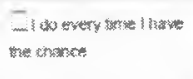 \\
\hline & & & \multicolumn{2}{|c|}{ 10. Subtotal } \\
\hline $\begin{array}{l}\text { 17. I voluntuer in thing: that I ant } \\
\text { intarested of. }\end{array}$ & 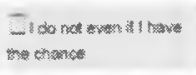 & 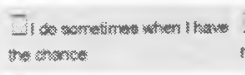 & 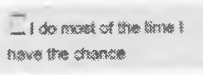 & 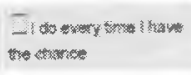 \\
\hline 38. I go to restaknants that I ske. & 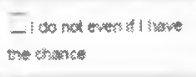 & 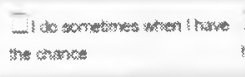 & 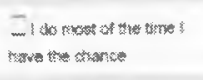 & 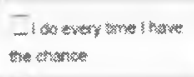 \\
\hline $\begin{array}{l}\text { 19. I go to mowers, concerts, and } \\
\text { daxuces. }\end{array}$ & 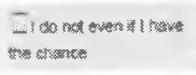 & 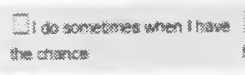 & In host of the time: & 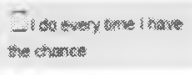 \\
\hline 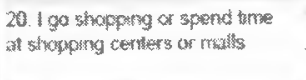 & 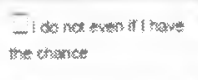 & 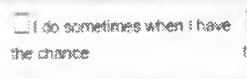 & $\begin{array}{l}\text { If to most of the ins } \\
\text { trave to ctsance }\end{array}$ & - 1 do wery the ing \\
\hline 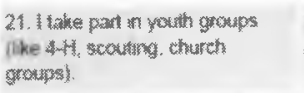 & 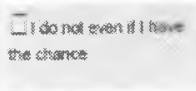 & 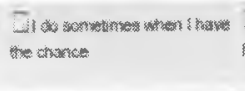 & 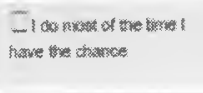 & 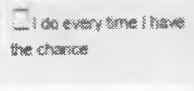 \\
\hline
\end{tabular}




\begin{tabular}{|c|c|c|c|c|}
\hline 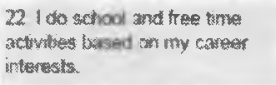 & 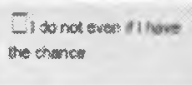 & 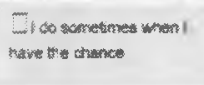 & I we mos of the bine I have & 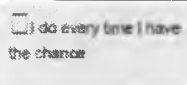 \\
\hline $\begin{array}{l}\text { 23. I work on school work that } \\
\text { will morove my caneer chances. }\end{array}$ & 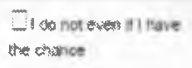 & 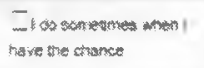 & 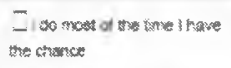 & 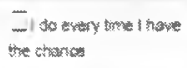 \\
\hline $\begin{array}{l}24 \text { I rxihe kony range cureer } \\
\text { pans. }\end{array}$ & 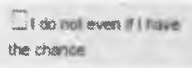 & $\begin{array}{l}\text { Tiso woretries smemi } \\
\text { nave the chances }\end{array}$ & 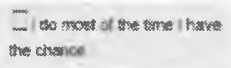 & 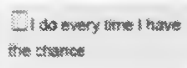 \\
\hline $\begin{array}{l}\text { 25. I work or have worked to } \\
\text { eam money. }\end{array}$ & 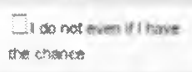 & 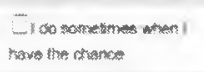 & 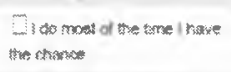 & 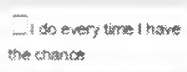 \\
\hline $\begin{array}{l}\text { 26. I am in or have been in cat } \\
\text { reer or at classes or trainung }\end{array}$ & $\begin{array}{l}\text { EI co not ever it i have } \\
\text { the thance }\end{array}$ & 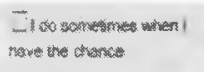 & 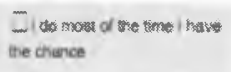 & 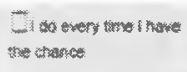 \\
\hline 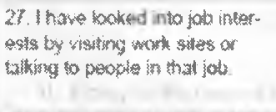 & $\begin{array}{l}\text { El a not even if I nave } \\
\text { the ctrance }\end{array}$ & $\begin{array}{l}\text { - to somednieo when I } \\
\text { tove the crance }\end{array}$ & 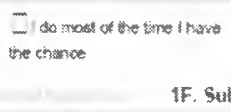 & $\begin{array}{l}\text { If do every tme I have } \\
\text { btotal }\end{array}$ \\
\hline $\begin{array}{l}28 \text { I choose my cloifhes and fhe } \\
\text { personal items I use every day. }\end{array}$ & 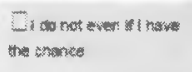 & 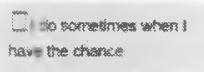 & 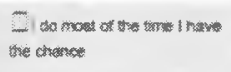 & $\begin{array}{l}\text { Ei so every tore i have } \\
\text { the chance }\end{array}$ \\
\hline 29. I choose ny own hairstyle. & 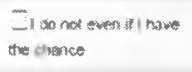 & 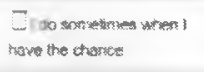 & $\begin{array}{l}\text { Di co moat of the sime inase } \\
\text { the chance }\end{array}$ & 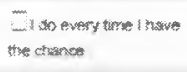 \\
\hline $\begin{array}{l}30 \text { I choose gits to give to tam } \\
\text { ily and friends. }\end{array}$ & $\begin{array}{l}\text { El wo nod even of I tave: } \\
\text { the wrance }\end{array}$ & 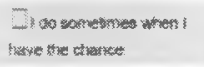 & 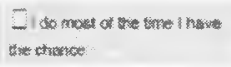 & 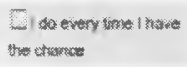 \\
\hline 31. t tecorate my oun room & Eitoonot exen is have & 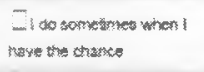 & -iso mot of the time then & $\begin{array}{l}\text {-1 do every time l thave } \\
\text { the chance }\end{array}$ \\
\hline $\begin{array}{l}\text { 32. I chase how to stord my } \\
\text { personal money }\end{array}$ & $\begin{array}{l}\text { Ei dos not even if i hase } \\
\text { the crances }\end{array}$ & $\begin{array}{l}\text { Disc schwarne when! } \\
\text { nase tre crance }\end{array}$ & 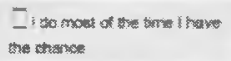 & - I do every thines in have \\
\hline
\end{tabular}

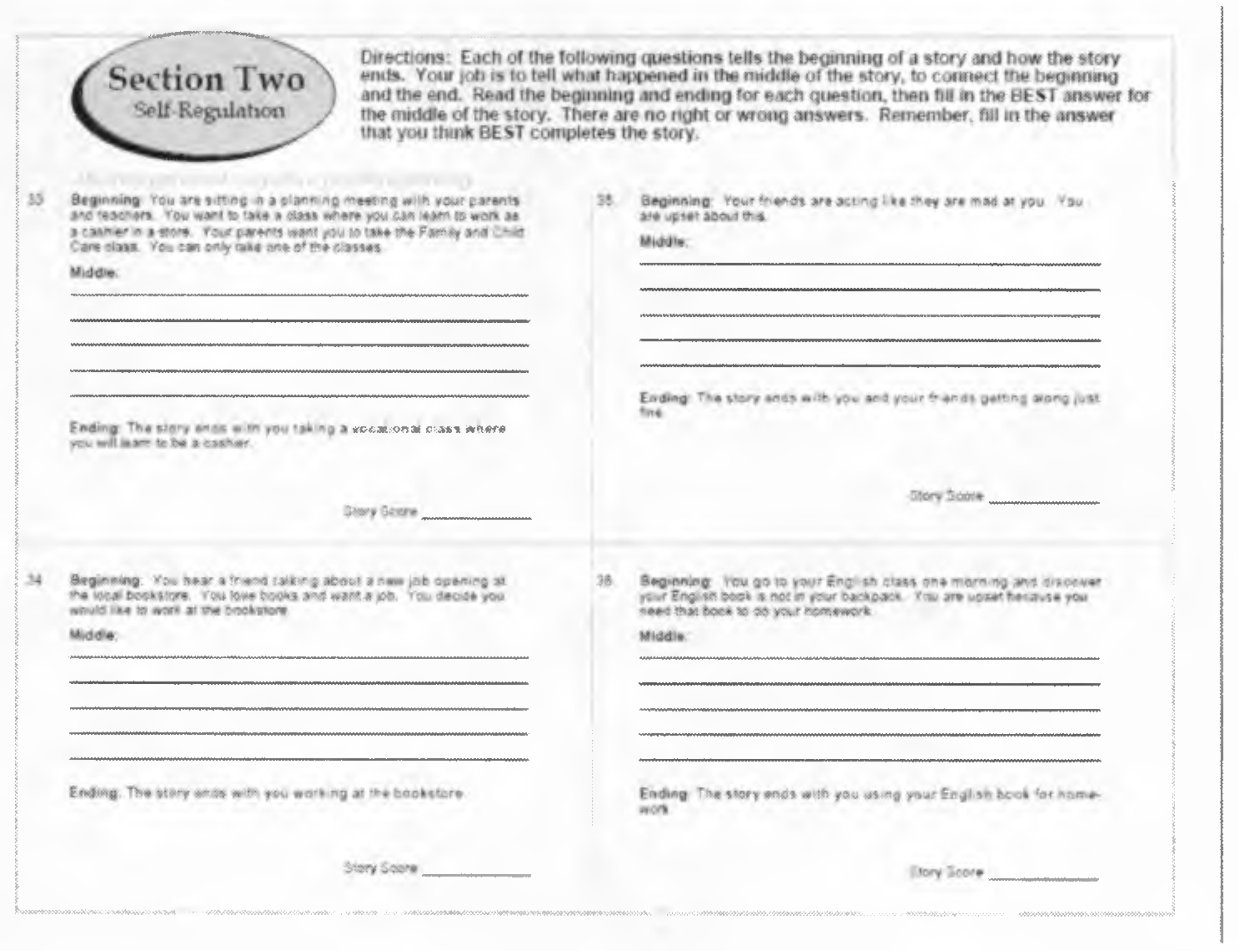



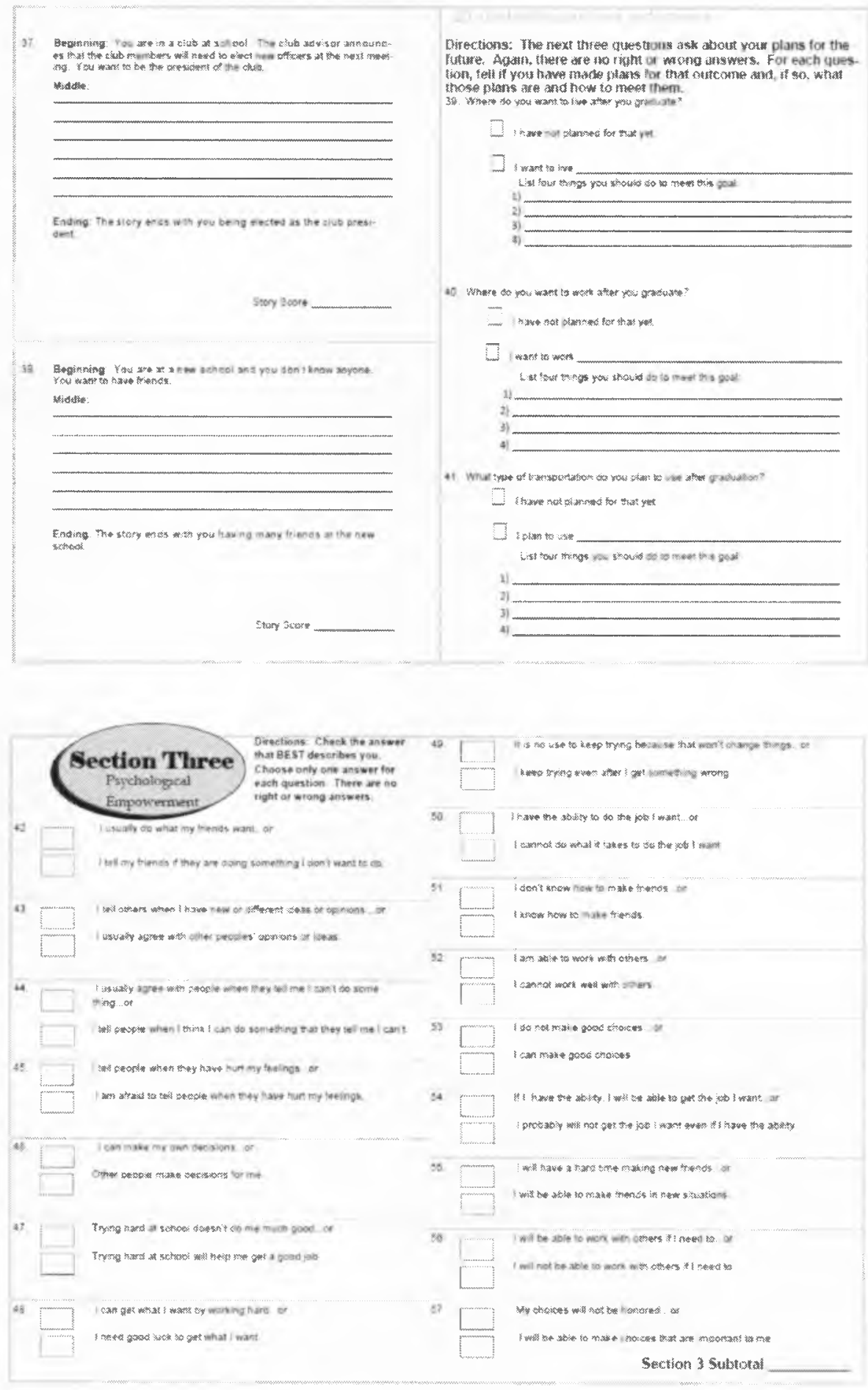


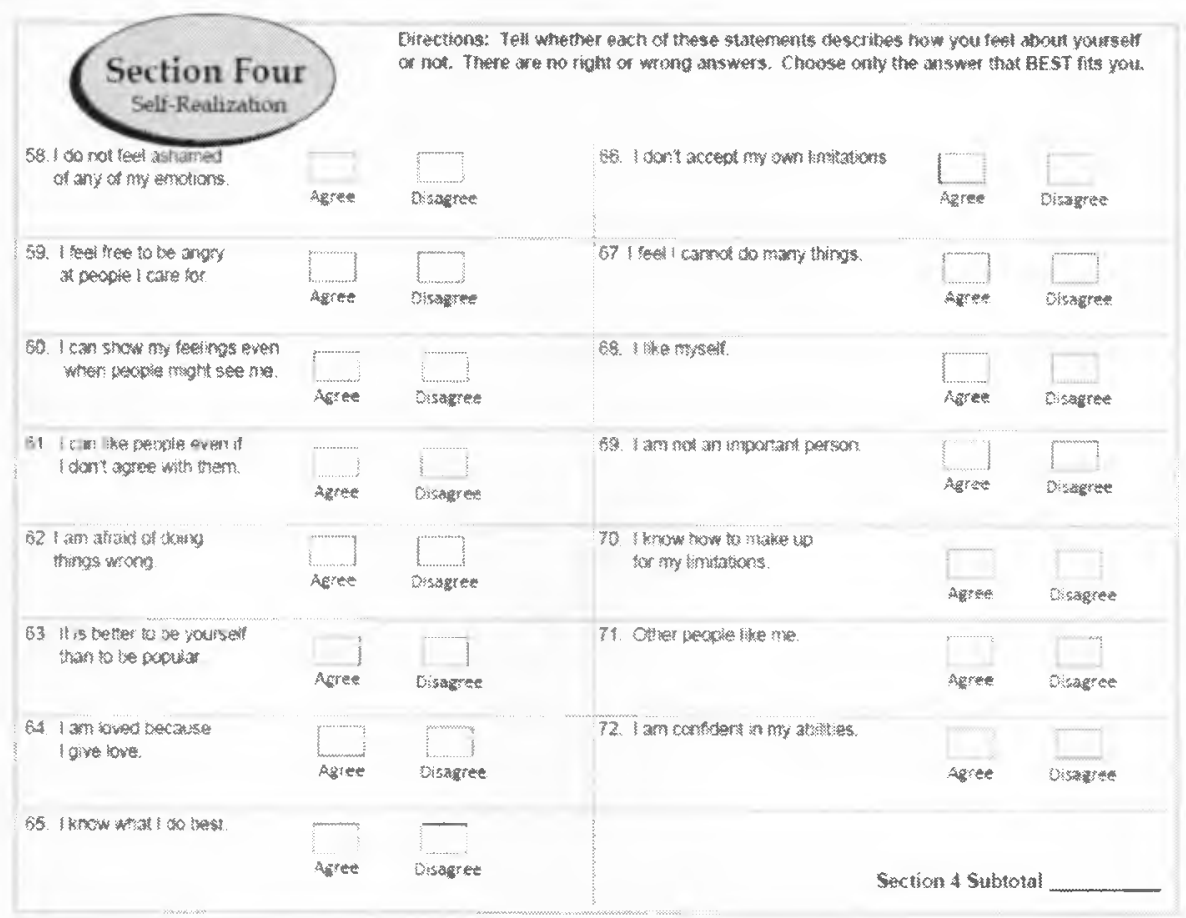

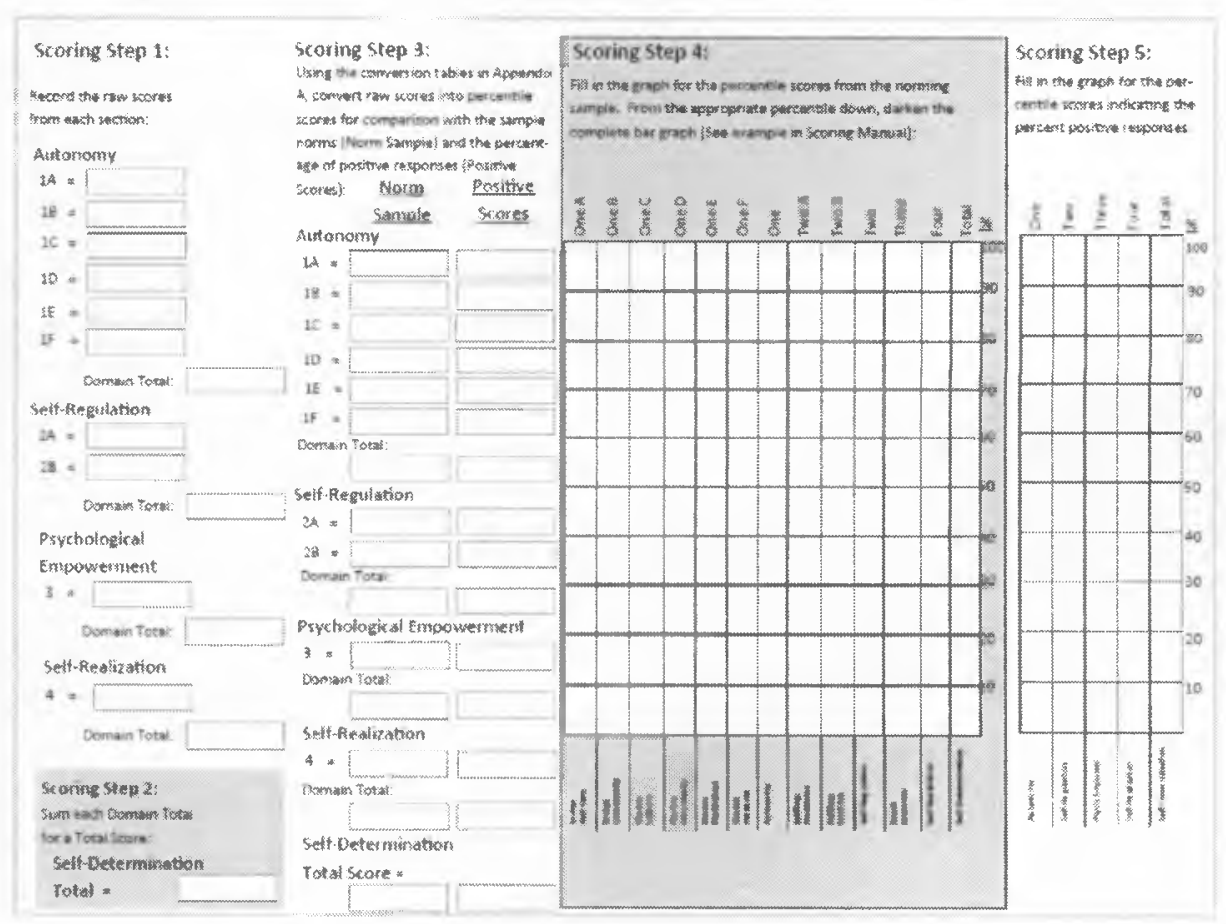




\section{Appendix C: Semi-Structured Interview Questions}

The semi-structured interview questions are listed below:

1) Besides academic subject knowledge, what are the most essential characteristics you need to be successful in college? Why? What skills? What behaviors? What attitudes? Did you know this when you were in high school?

2) How prepared were for college? What were your challenges?

3) Have you accessed disability resource or disability services? When? How did you do access it?

4) How aware of your disability? What are your strengths? What are your challenges?

5) Have you communicated to your college professors about your disability? What accommodations do you use in your classes? Did you have to ask for them? How has it impacted your 1st semester in college?

6) Do other people's perception of disability affect how you are treated in college? How has that impacted you and your work?

7) If you were to give advice to high school students with learning disabilities who will be graduating soon, what advice would you give them? Why?

8) If you were to give advice to your former high school teachers on how to prepare you better for college, what would you suggest them? Why? 